\title{
Advances in Porous Scaffold Design for Bone and Cartilage Tissue Engineering and Regeneration
}

\author{
Alice Cheng, PhD, ${ }^{1,2}$ Zvi Schwartz, DDS, PhD,,4 Adrian Kahn, DMD, Xiyu Li, PhD,,2 Zhenxing Shao, PhD, \\ Muyang Sun, PhD, Yingfang Ao, MD, Barbara D. Boyan, $\mathrm{PhD}^{2,3}$ and Haifeng Chen, $\mathrm{PhD}^{1}$
}

Tissue engineering of bone and cartilage has progressed from simple to sophisticated materials with defined porosity, surface features, and the ability to deliver biological factors. To avoid eliciting a foreign body response due to inclusion of allogeneic cells, advances in functional scaffold design harness the endogenous ability of the body to regenerate. We review advancements in the surface and structural properties of typical polymeric, ceramic, and metallic scaffolds for orthopedic use. First, we provide an overview of methods and materials, with a focus on additive manufacturing and electrospinning. Multidimensional physical properties of scaffolds, including three-dimensional macrostructure, pore design, and two-dimensional hierarchical surface roughness, allow tissue regeneration at different spatial and temporal scales. Enhanced biological response can be achieved through surface functionalization and the use of exogenous factors. Finally, different in vitro and in vivo models are discussed for translation of these technologies for clinical use.

Keywords: tissue engineering, bone and cartilage, additive manufacturing, scaffold design

\section{Impact Statement}

Challenges in musculoskeletal tissue regeneration affect millions of patients globally. Scaffolds for tissue engineering bone and cartilage provide promising solutions that increase healing and decrease need for complicated surgical procedures. Porous scaffolds have emerged as an attractive alternative to traditional scaffolds. However, the success of advanced materials, use of biological factors, and manufacturing techniques can vary depending on use case. This review provides perspective on porous scaffold manufacturing, characterization and application, and can be used to inform future scaffold design.

\section{Introduction}

Cientists And THE public have long dreamed of the bi$\checkmark$ onic human, complete with artificial organs. Tissue engineering approaches are well underway to regenerate the most complex of tissues. Most of these technologies have remained in the laboratory, although the clinical need is great. By 2030, 572,000 total hip and 3.48 million total knee replacements are expected to occur in the United States each year. ${ }^{1}$ In addition, 96,700 hip revisions and 268,200 knee revision procedures are projected to occur annually. The staggering growth of procedures points toward a need for regenerative solutions for bone and cartilage that are scalable, and can remain successful throughout the life of the patient.
Tissue engineering scaffolds provide a promising way to repair and regenerate damaged tissues by mimicking the structural and functional profile of the natural extracellular matrix (ECM). An ideal scaffold should have the appropriate surface chemistry, biocompatibility (optimizing for decreased inflammation and immune response), porosity and mechanical properties to integrate with the native host tissue. ${ }^{2}$ Bone and cartilage are included under the orthopedic umbrella, but are very different tissues, and require different approaches to regenerate. Bone is highly vascularized, with most blood vessels located within $100 \mu \mathrm{m}$ of osteoblasts synthesizing and mineralizing bone matrix (osteoid). ${ }^{3}$ Thus, most tissue engineering approaches for bone attempt to increase vascularization. In contrast, cartilage is avascular. ${ }^{4}$

\footnotetext{
${ }^{1}$ Department of Biomedical Engineering, Peking University, Beijing, China.

${ }^{2}$ Wallace H. Coulter Department of Biomedical Engineering, Georgia Institute of Technology and Emory University, Atlanta, Georgia.

${ }^{3}$ Department of Biomedical Engineering, Virginia Commonwealth University, Richmond, Virginia.

${ }^{4}$ Department of Periodontology, University of Texas Health Science Center at San Antonio, San Antonio, Texas.

${ }^{5}$ Department of Oral and Maxillofacial Surgery, University of Tel Aviv, Tel Aviv, Israel.

${ }^{6}$ Institute of Sports Medicine, Peking University Third Hospital, Beijing, China.
} 
Although bone and cartilage are two quite different tissues, their development is still interrelated. For example, the transcription factor Sox9 is expressed in chondrocytes and regulates chondrogenesis, but it also suppresses the later stages of osteochondral bone formation by negatively regulating vasculogenesis. ${ }^{5}$ Thus, orthopedic tissue engineering strategies should also consider their impacts on neighboring tissues.

A tissue engineering approach not only includes the physical properties of the scaffold, but also biological factors that can enhance regeneration. Instead of building a one-sizefits-all solution in the laboratory, successful functional scaffold design harnesses the natural regeneration abilities of the human body. While the natural healing cascade is complex and varies between bone and cartilage, it is necessary to understand this basic biology to inform biomaterial design. ${ }^{6,7}$ Scaffold design strategies include peptides for cell homing and attachment, proteins for creating a favorable microenvironment, and cells to facilitate early ECM formation (Fig. 1). While challenges still exist for bone and cartilage regeneration, progress in these methods highlights advances in our understanding of the biological response to biomaterials. In this review, we provide an overview of scaffold composition and geometry, then focus on two major approaches for manufacturing porous scaffolds, methods for modifying surface roughness and surface functionalization, and finally the use of biological models for scaffold evaluation.

\section{Scaffold Composition and Geometry}

Scaffolds for bone and cartilage tissue engineering are composed of a variety of materials. Synthetic polymers vary in cost and are generally more readily available than natural materials, but can have large batch variation. Most commonly used synthetic polymers include polyglycolic acid (PGA), polylactic acid (PLA), polylactide-co-glycolide (PLGA), and polycaprolactone (PCL) ${ }^{8,9}$ Varying ratios and combinations of these biodegradable polymers can be used to customize surface, mechanical, and structural properties. Varying surface chemistry can lead to changes in wettability. ${ }^{10}$ By modifying chain length, including protease-sensitive linkages, and using racemic mixtures, the polymers can be designed to degrade rapidly or up to years after implantation. In addition, mechanical properties of the scaffold can be optimized to serve different structural purposes throughout the regeneration process. These possibilities make them ideal for delivering drugs or growth factors, and for serving as structural scaffolds that are eventually replaced with new tissue. ${ }^{11}$ Shape memory polymers such as polycaprolactone dimethacrylate are also attractive for their ability to increase scaffold size after being exposed to a specific stimulus in the body, thus facilitating implantation through a smaller wound site. ${ }^{2}$ Changes in surface roughness at the microscale can also be used to influence cell attachment and proliferation during initial implantation, followed by osteoblastic differentiation over time. ${ }^{13}$

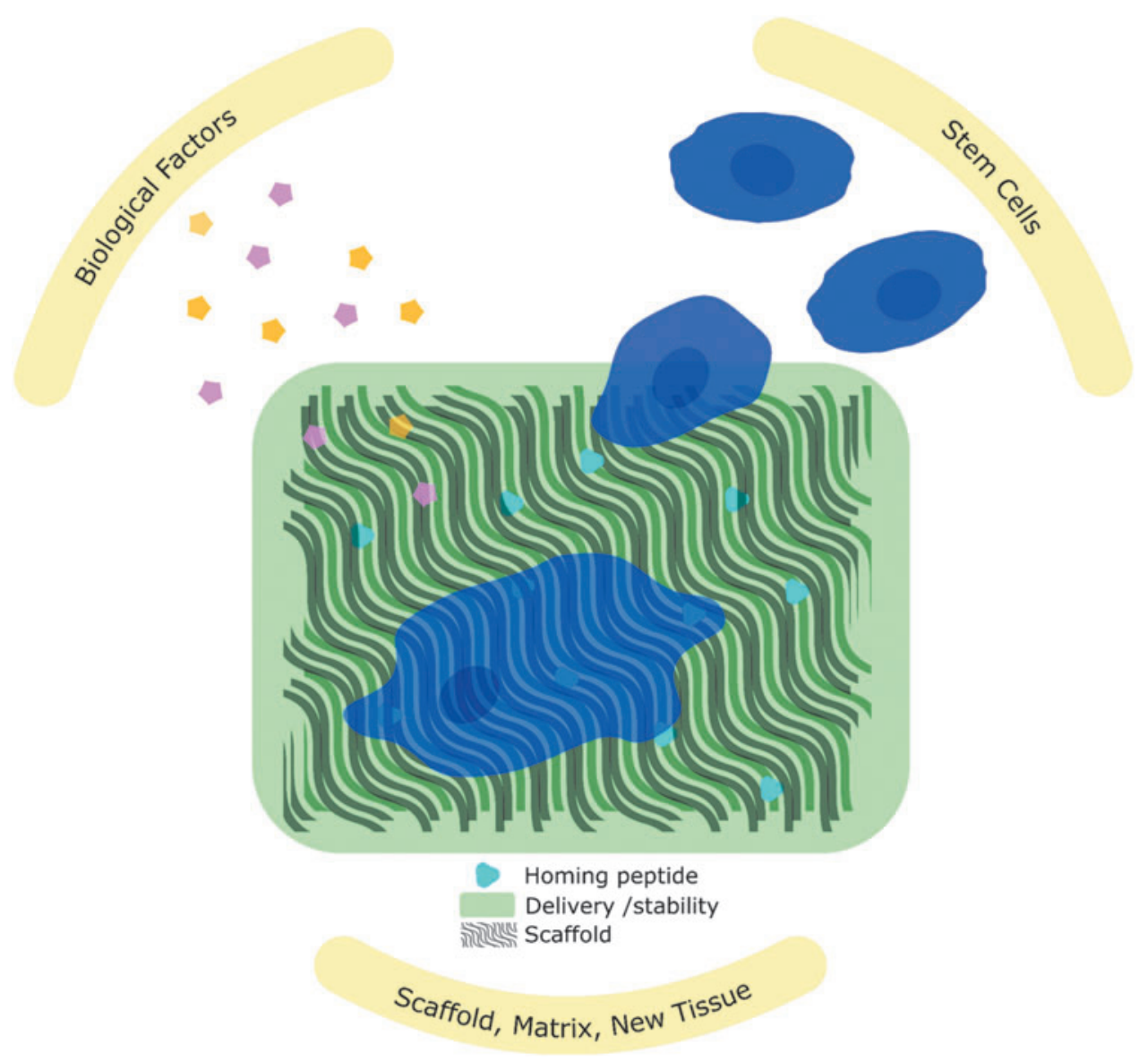

FIG. 1. Scaffolds that harness the natural regeneration processes of the body to recruit endogenous stem cells and biological factors for tissue regeneration. 
In addition to synthetic polymers, polymers found in nature are frequently used for tissue engineering applications. Collagen type I, a major component of connective tissue, is most commonly used to mimic the structure and composition of the natural ECM. Polysaccharides such as chitosan and polypeptides such as silk fibroin are other naturally derived polymers that have been used for bone or cartilage tissue engineering scaffolds. ${ }^{14,15}$ Silk fibroin scaffolds have shown promise for cartilage tissue engineering due to their mechanical properties and versatility. Most recently, 3D printing has been used to create silk-fibroin-gelatin scaffolds that have shown success for cartilage repair both in vitro using bone marrow-derived stem cells, and in vivo in rabbits. ${ }^{16}$ Silk hydrogels, porous sponges, and electrospun silk are also approaches to support cartilage regeneration through a tissue engineering scaffold. ${ }^{15,17,18}$ Additionally, hydrogels can be composed of a variety of polymers to provide substantially different mechanical and structural properties.

Decellularized matrices attempt to provide a more natural environment for cell infiltration and tissue growth due to their retention of the native ECM structure, and are a promising alternative to autografts. ${ }^{19}$ While demineralized bone matrix (DBM) is a decellularized tissue commonly used clinically and adopted at the industry level, ongoing laboratory studies are exploring the potential for decellularized cartilage, skeletal muscle, and other musculoskeletal tissues. ${ }^{19,20}$ However, manufacturing challenges prevent scalability of these solutions for clinical use. The decellularization process requires optimization, and currently lacks standardization across the industry.

Ceramic scaffolds such as calcium phosphate, bioglass, and titanium are used heavily in bone tissue engineering applications, where mechanical strength is important. Hydroxyapatite scaffolds resemble the natural composition of bone, and can be manufactured with varying porosities to enhance bone ingrowth. ${ }^{21}$ For bone tissue engineering scaffolds, metals and ceramics are preferred for their mechanical properties and biological compatibility. Titanium and its alloys are attractive metals because of a naturally occurring $\mathrm{TiO}_{2}$ oxide layer that increases corrosion resistance and contributes to hardness at the surface. This naturally occurring oxide layer is also naturally hydrophilic, although can quickly become hydrophobic as it is exposed to hydrocarbons in the atmosphere. Hydrophilic microrough $\mathrm{TiO}_{2}$ substrates preserved in solution decreased osteoblast proliferation and spreading, while increasing osteoblastic differentiation compared with their more hydrophobic counterparts that were stored under dry conditions. ${ }^{22}$ Silicon-based bioglass is a ceramic that is defined by the formation of hydroxyapatite-like surface layer upon immersion in simulated body fluid. ${ }^{23}$ However, use of bioglass is limited by its degradation properties and brittleness. ${ }^{23}$

At the most basic level, the function of tissue engineering scaffolds is to serve as a mechanical support for regeneration of tissue, especially in load-bearing areas. However, the macro and micro structure of scaffolds must also allow cell and tissue infiltration, as well as blood vessel and nerve growth. ${ }^{24}$ Thus, the size scale and structure of pores within the scaffold must be considered for optimal biological response. For nondegradable scaffolds, pore diameters over $100 \mu \mathrm{m}$ have been considered necessary for cell attachment, and pore diameters over $300 \mu \mathrm{m}$ for tissue growth. ${ }^{25,26}$ Other studies using biodegradable materials indicate that scaffolds with smaller pore sizes can also be effective. ${ }^{27,28}$

Porosity can also indirectly affect cell response by altering the fluid shear forces on the cell. While it is difficult to recapitulate the in vivo environment exactly in cell culture, studies have shown that cells are indeed influenced by mechanical forces resulting from fluid flow, and that these flows are altered based on scaffold porosity. ${ }^{29,30}$ Additional studies have shown the importance of smaller micropores and the role of morphology in facilitating protein adsorption. ${ }^{31}$ With little consensus on the ideal pore diameter or morphology, perhaps the best option is to create scaffolds with porosity gradients to serve specific functions throughout the regeneration process. ${ }^{26}$

As scaffold design becomes more sophisticated, multiple parameters for characterizing porosity should be considered. Simple parameters such as total percent porosity and pore diameter are now being supplemented with more descriptive characteristics, such as channel tortuosity and surface area to volume ratio (Table 1). Characterization of pores has also advanced to include pore shape and curvature. It is important to fully characterize scaffolds based on standardized parameters to reproduce and evaluate results across biological studies.

\section{Scaffold Manufacturing}

Traditional methods for porous scaffold manufacturing techniques include foam processing, solvent casting, and freeze drying. ${ }^{2}$ These methods allow limited control over scaffold chemistry, macrostructure, and porosity. Other methods have been proposed to address issues in scalability, sustainability, and spatial control (Table 2 and Fig. 2). ${ }^{32-37}$ Advances in manufacturing have allowed the development of two main technologies for producing tunable scaffolds for tissue engineering: electrospinning and additive manufacturing.

\section{Electrospinning}

Electrospinning is a technique that is able to produce microand nanoscale fibers from polymers and composite materials with tunable diameter, porosity, surface morphology, and fiber alignment. $^{38,39}$ Due to a large surface area and high porosity, electrospun scaffolds can be used for tendon-to-bone, cartilageto-bone, and cartilage tissue engineering applications. ${ }^{40,41}$ The use of coaxial and other electrospinning techniques has also allowed development of composite electrospun scaffolds.

Electrospinning has been applied to polymers and ceramic materials. ${ }^{42,43}$ Natural polymers, such as collagen ${ }^{44}$ and silk fibroin, ${ }^{45}$ have been proposed to avoid inflammation and foreign body reaction when implanted in vivo. While the main organic ECM component of bone is collagen type I, the presence of collagen type II dominates in cartilage; both have been employed in electrospinning scaffold applications. ${ }^{4,46}$ Synthetic polymers are also commonly used; they are less expensive and have more consistency across batches. The most commonly used synthetic polymers include PCL, PLA, and PLGA. ${ }^{4-49}$ For cartilage tissue engineering, polymer electrospinning has been combined with hydrogels through various processing techniques, which provides both structure and function. ${ }^{50}$ 
Table 1. Parameters for Porous Scaffold Characterization

\begin{tabular}{|c|c|c|}
\hline Parameter & Definition & Biological response \\
\hline Total porosity & Percentage of total void space & $\begin{array}{l}\text { Total porosity also affects mechanical strength of the scaffold, which } \\
\text { is especially important for load-bearing applications. An ideal } \\
\text { scaffold would mimic the Young's modulus of 3-20 GPa for bone } \\
\text { and } 10 \mathrm{MPa} \text { for cartilage. }\end{array}$ \\
\hline Open porosity & $\begin{array}{l}\text { Percentage of pores that are } \\
\text { interconnected }\end{array}$ & $\begin{array}{l}\text { Interconnected pores can affect cell permeability and tissue } \\
\text { infiltration, as well as growth factor diffusion. For bone, open } \\
\text { porosity is necessary to increase vascularization and can be } \\
\text { measured in scaffolds through microCT or mercury intrusion } \\
\text { porosimetry. }\end{array}$ \\
\hline Tortuosity & $\begin{array}{l}\text { Quantification of twists and } \\
\text { turns through a connected } \\
\text { channel, expressed as the }\end{array}$ & $\begin{array}{l}\text { In addition to affecting surface area, tortuosity of scaffold channels } \\
\text { can also affect cell migration and delivery and removal of nutrients } \\
\text { and waste, respectively. }\end{array}$ \\
\hline
\end{tabular}
length of the entire channel divided by the shortest distance between starting and ending points.

Surface area to volume ratio

Pore diameter

Diameter of largest sphere that fits within pore channel

Strut thickness

Also known as "trabecular thickness," the thickness of structural supports within the scaffold

Pore curvature Radius of curvature

Pore circularity

Although not a standard definition, pore circularity refers to the similarity of pore channel cross-sections to circles

Pore gradient

Difference in pore diameter, total porosity, or other porosity parameter. This is not standardized and can be expressed in multiple ways.

Stiffness

Mechanical property commonly expressed in units of $\mathrm{kPa}$.

Swelling ratio

\section{The ratio of wet mass or volume to dry mass or volume of a hydrogel}

Total porosity also affects mechanical strength of the scaffold, which is especially important for load-bearing applications. An ideal scaffold would mimic the Young's modulus of 3-20 GPa for bone

infiltration, as well as growth factor diffusion. For bone, open porosity is necessary to increase vascularization and can be measured in scaffolds through microCT or mercury intrusion can also affect cell migration and delivery and removal of nutrients and waste, respectively.

Surface area to volume should be considered when choosing cell seeding density and concentration of functionalized factors on scaffolds for in vitro studies. Degradation rates may also be affected in degradable scaffolds, impacting drug release.

The size of pores has been investigated extensively for facilitating bone growth, with no clear consensus on the optimal pore diameter. While pores over $100 \mu \mathrm{m}$ are generally preferred for cell infiltration and bone ingrowth, recent studies suggest that smaller pores may be preferable during later stages of growth.

Strut thickness is typically inversely correlated with porosity and pore diameter, thus affecting cell penetration tissue growth into the scaffold.

The degree of concave or convex surface curvature can affect cell contraction and focal adhesion formation.

Circular, triangular, square and hexagonal pore cross sections influence cell growth and ECM deposition differently.

Localized and gradient porosity have been proposed to increase tissue-specific growth during the regeneration process. This allows nutrient transport throughout the scaffold based on the scaffold and tissue architecture.

Stiffness of a substrate can affect MSC differentiation into osteoblasts, which is mediated by integrin signaling. Stiffness is typically inherent in a material's composition, but may also change over time for degradable scaffolds or shape memory polymers. Dynamic hydrogels also provide a model for understanding cell response to changes in ECM stiffness during disease and development.

Swelling can affect delivery of growth factors or oxygen diffusion, leading to changes in cell response. Rate of swelling may also affect cell attachment and proliferation.

ECM, extracellular matrix; MSC, mesenchymal stem cell.

The morphology of electrospun nanofibers can be manipulated by controlling the parameters for electrospinning. By using a rotating mandrel as the collector, it is possible to produce aligned fibers to mimic the parallel bundles of collagen fibrils, ${ }^{40}$ and tunable crimped nanofibers to vary mechanical strength. ${ }^{48}$ Besides mimicking the ECM, the alignment of electrospun nanofibers can also guide cell attachment migration. Initial work on electrospinning PLGA scaffolds for cartilage tissue engineering sought to mimic the native structure of collagen fibrils, and resulted in electrospun fibers ranging from 500 to $800 \mathrm{~nm}$ in diameter. ${ }^{51}$ Recent work suggests that chondrocytes may prefer larger 
Table 2. Porous Scaffold Manufacturing Techniques

Technique

Freeze casting

Freeze drying/lyophilization

Solvent casting and particulate leaching

Gas foaming

Phase separation

Electrospinning

Sol-gel

Additive manufacturing
Applications

Ceramic slurries are most commonly freeze cast, where water from the slurry is sublimated and results in pores with the morphological characteristics of ice crystals.

A relatively simple technique that can be used with natural materials such as collagen, gelatin, or silk fibroin, the porosity can be modified based on changes in freezing temperature and material concentration.

For three-dimensional scaffolds, molds must be created for casting the polymer solution. Although leaching requires additional processing time, the use of organic solvents facilitates addition of drugs or growth factors to scaffolds.

Carbon dioxide at high pressure is used to expand the polymer instead of using temperature or other solvents. Varying pressure can also produce scaffolds with a gradient porosity.

Thermally induced phase separation can be used to separate polymers into their solvent and solid polymer, resulting in homogenous and interconnected porosity throughout the scaffold that can be tunable based on cooling rates during processing.

Electrospun fibers can vary from nanoscale to microscale, with alignment and chemical composition based on processing parameters. Previously restricted to polymers, recent advances have also allowed for electrospinning of titanium for bone tissue engineering.

Traditionally used colloidal metal oxides, the sol-gel method results in a scaffold with tunable porosity and chemistry. Biphasic chitosan scaffolds with an affinity peptide have shown the ability to recruit stem cells for cartilage regeneration.

Extrusion methods are mostly polymer based. Solid freeform through sintering can be applied to both polymers and metals, while laser melting is restricted to metals.

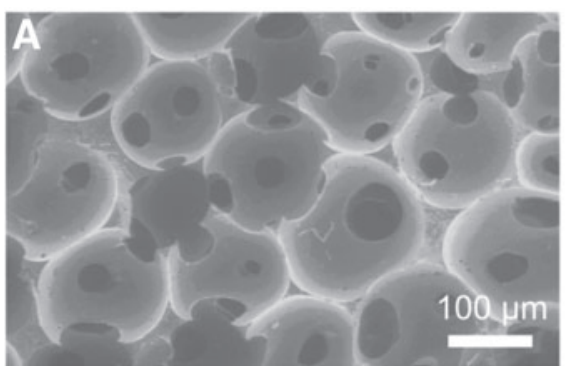

B
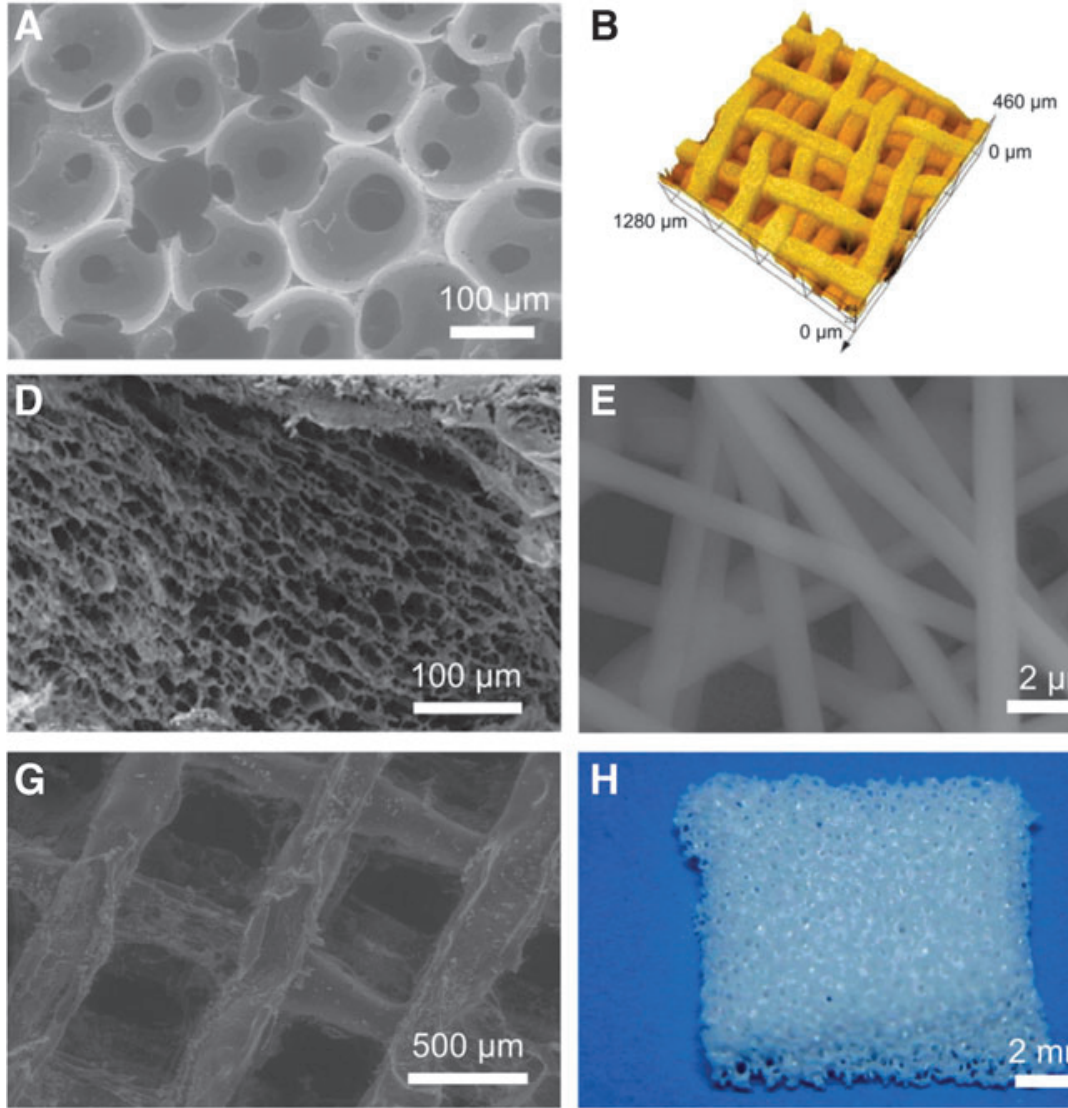

E
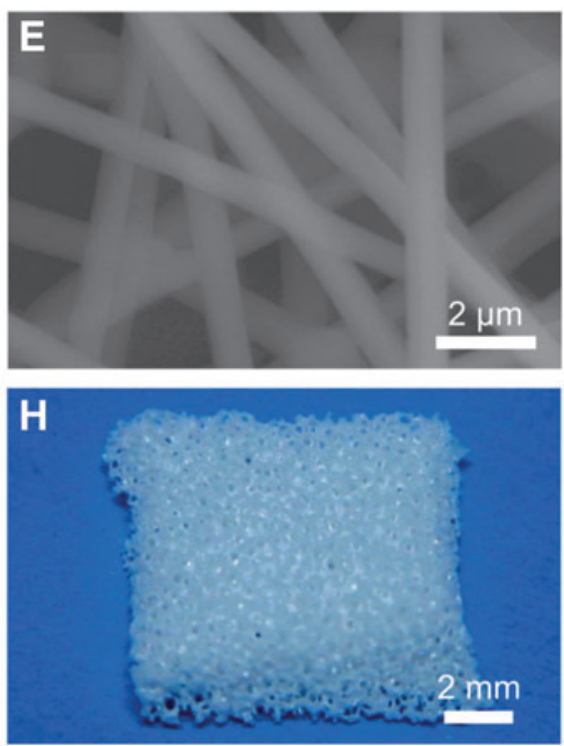
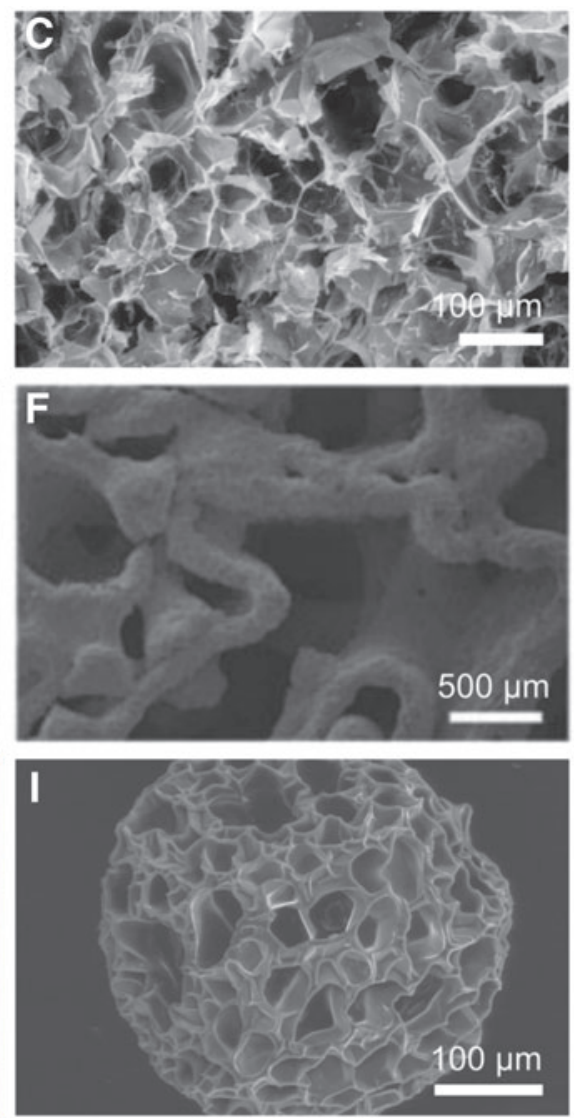

FIG. 2. Different manufacturing techniques for porous scaffolds. Freeze-dried polyurethane scaffold (A), pressed TiO2 scaffolds (B), thermal polymerizable alginate-glycidyl methacrylate freeze-dried hydrogen scaffold (C), demineralized bone matrix coated with a chitosan thermogel (D), electrospun PEO/PPy conductive scaffolds (E), direct metal laser sintered Ti-6Al-4V scaffold from human trabecular bone template (F), fibroin-gelatin mixture poured into 3D printed, dissolvable polystyrene mold (G), zirconia slurry poured into freeze-dried and dissolvable polyurethane scaffold to achieve porous, fully zirconia scaffold $(\mathbf{H})$, agarose-gelatin microbead produced through a microfluidic system (I). E, F adapted from Whang et al. and Shimko et al. ${ }^{28,30}$ 
microscale fiber diameters on electrospun scaffolds over nanoscale fiber diameters. ${ }^{52}$ These mimic the natural range of collagen fibrils, which vary based on zone and patient age. ${ }^{53}$

Composite electrospun scaffolds have been produced that combine advantages of the biological performance of natural polymers and the mechanical properties of synthetic polymers. Ceramic scaffolds using hydroxyapatite ${ }^{54}$ or $\mathrm{TiO}_{2}{ }^{55}$ have been manufactured as bone graft substitutes for bone repair. In one study, $\mathrm{TiO}_{2}$ nanofiber mats were generated that had nanofiber diameters of mostly $100-300 \mathrm{~nm}$ with $6 \%$ polyvinylpyrrolidone (PVP) and 300-500 nm with $10 \% \mathrm{PVP}^{56}$ MG63 osteoblasts on larger diameter $\mathrm{TiO}_{2}$ scaffolds made with $10 \%$ PVP also produced higher levels of osteocalcin compared with cells on smaller diameter scaffolds. In addition, osteocalcin, osteoprotegerin, and vascular endothelial growth factor (VEGF) were higher on the patterned side of the scaffold compared with the flat side for scaffolds made with 10\% PVP. Osteocalcin and VEGF were not higher for patterned scaffolds made with $6 \%$ PVP compared with smooth scaffolds of the same composition, indicating that the response to surface characteristics was also dependent upon nanofiber diameter. Three-dimensional titanium mesh scaffolds with microroughness induced by acid etching were also evaluated for their effects on osteoblast differentiation (Fig. 3). ${ }^{32} \mathrm{Com}-$ pared with the 2D group, 3D scaffolds with a submicronscale texture showed higher levels of osteoblast differentiation markers, and these effects were mediated by integrin $\alpha 2 \beta 1$. In follow-up studies, silica-titania nanofiber scaffolds also exhibited the ability to positively affect osteoblast differentiation in vitro. ${ }^{55}$

\section{Additive manufacturing}

Additive manufacturing has paved the way for patientspecific biomaterials, and holds much promise within the maxillofacial and orthopedic implant fields. ${ }^{57,58}$ Additive manufacturing also provides advantages in cost, scale, and flexibility over traditional manufacturing methods. ${ }^{59}$ The American Society for Testing and Materials has classified 7 different additive manufacturing processes based on deposition and bonding: photopolymer vat, material jetting, material extrusion, powder bed infusion, directed energy deposition, sheet lamination, and binder jetting. ${ }^{60}$ These methods have all been used for biomedical applications. For bone applications, powder bed fusion is most promising and includes selective laser sintering, selective laser melting, electron beam melting, and selective mask sintering. These methods can employ metals, such as titanium-aluminum-vanadium (Ti-6Al-4V), which have the mechanical ability to withstand the loads experienced by bone.

Tissue regeneration is dependent in part upon the macroscale scaffold architecture. For large bone defects, full vascularization into scaffolds has yet to be achieved and remains a challenge in scaffold design. ${ }^{61}$ While bone regeneration occurs on interconnected microporous scaffolds, cartilage regeneration is more successful on nanoporous scaffolds with less interconnectivity or smaller pore size, which leads to hypoxic conditions. ${ }^{62,63}$ Topological design studies suggest that bone interfacing scaffolds should mimic the mechanical properties of the native bone, but they have not yet offered an ideal porosity configuration that leads to the best biological response. ${ }^{64,65}$

Instead of homogenous porosity across the scaffold, recent studies have used additive manufacturing to create Ti$6 \mathrm{Al}-4 \mathrm{~V}$ constructs with trabecular bone-inspired porosity to enhance vascularization and osseointegration ${ }^{66,67}$ (Fig. 4A, B). Further work shows that while the MG63 osteoblast-like cell line and normal human osteoblasts (NHOsts) exhibit increased osteoblast differentiation maturation markers on $3 \mathrm{D}$ porous constructs compared with $2 \mathrm{D}$ surfaces manufactured
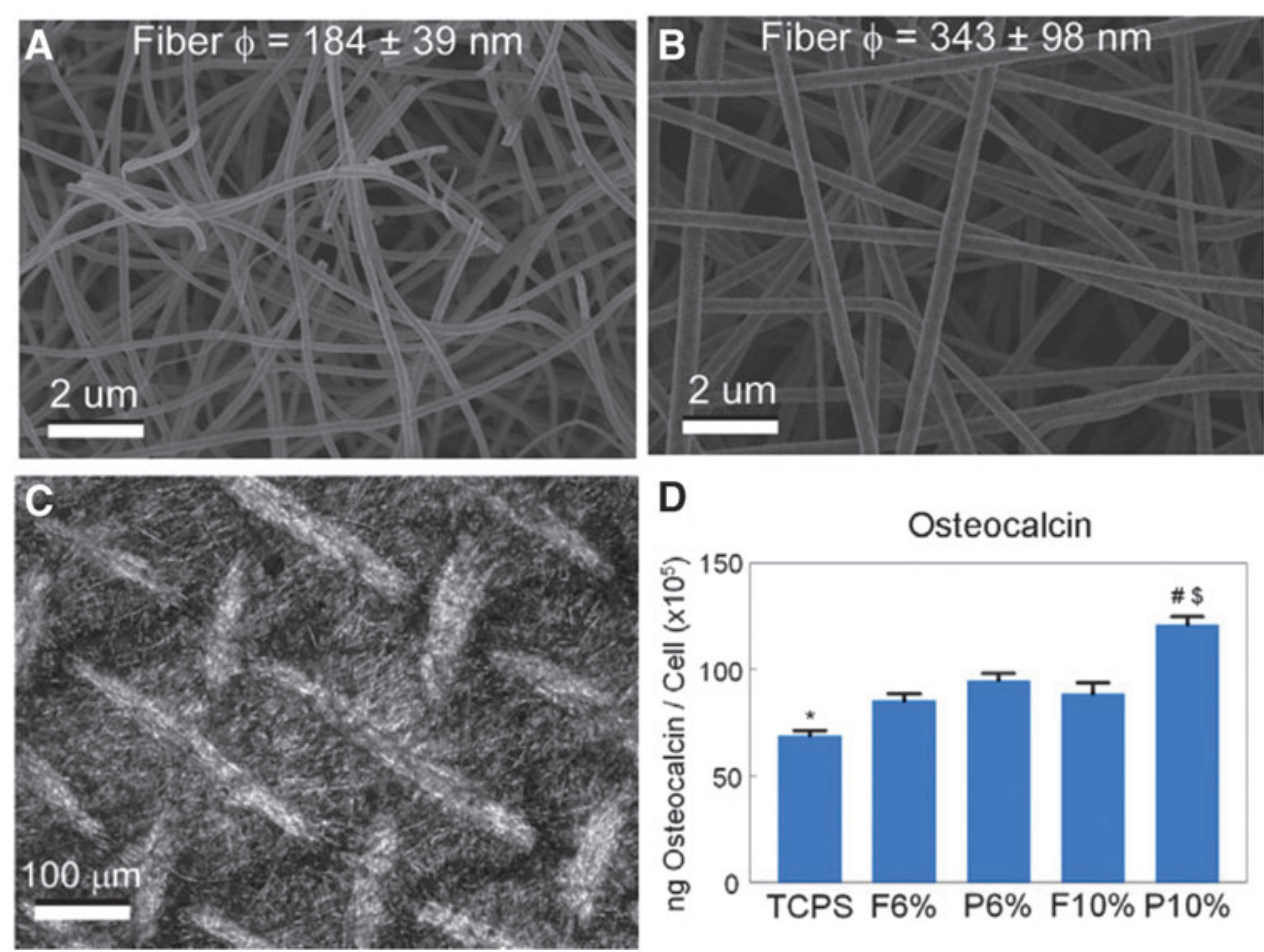

FIG. 3. The effect of electrospun nanofiber diameter and scaffold microstructure on biological response. $\mathrm{TiO}_{2}$ scaffolds with $6 \%$ PVP (A) had smaller fiber diameters than $\mathrm{TiO}_{2}$ scaffolds with $10 \%$ PVP (B). $\mathrm{TiO}_{2}$ scaffolds with $10 \%$ PVP that were additionally micropatterned $(\mathbf{C})$ induced the highest osteocalcin levels by osteoblasts (D). Statistical significance determined by $p$ value of $<0.05$; * vs. all $\mathrm{TiO}_{2}$ groups; \# vs. flat side of the same formulation; \$ vs. $6 \%$ PVP of the same side. PVP, polyvinylpyrrolidone. 
FIG. 4. Direct metal laser sintering is a form of additive manufacturing that can use a human trabecular bone template (A) to produce constructs with similar porosity (B). DMLS can also be used to produce patient-specific implants (C) that have been used clinically with patients with severe jaw atrophy (D). DMLS, direct metal laser sintering.
A
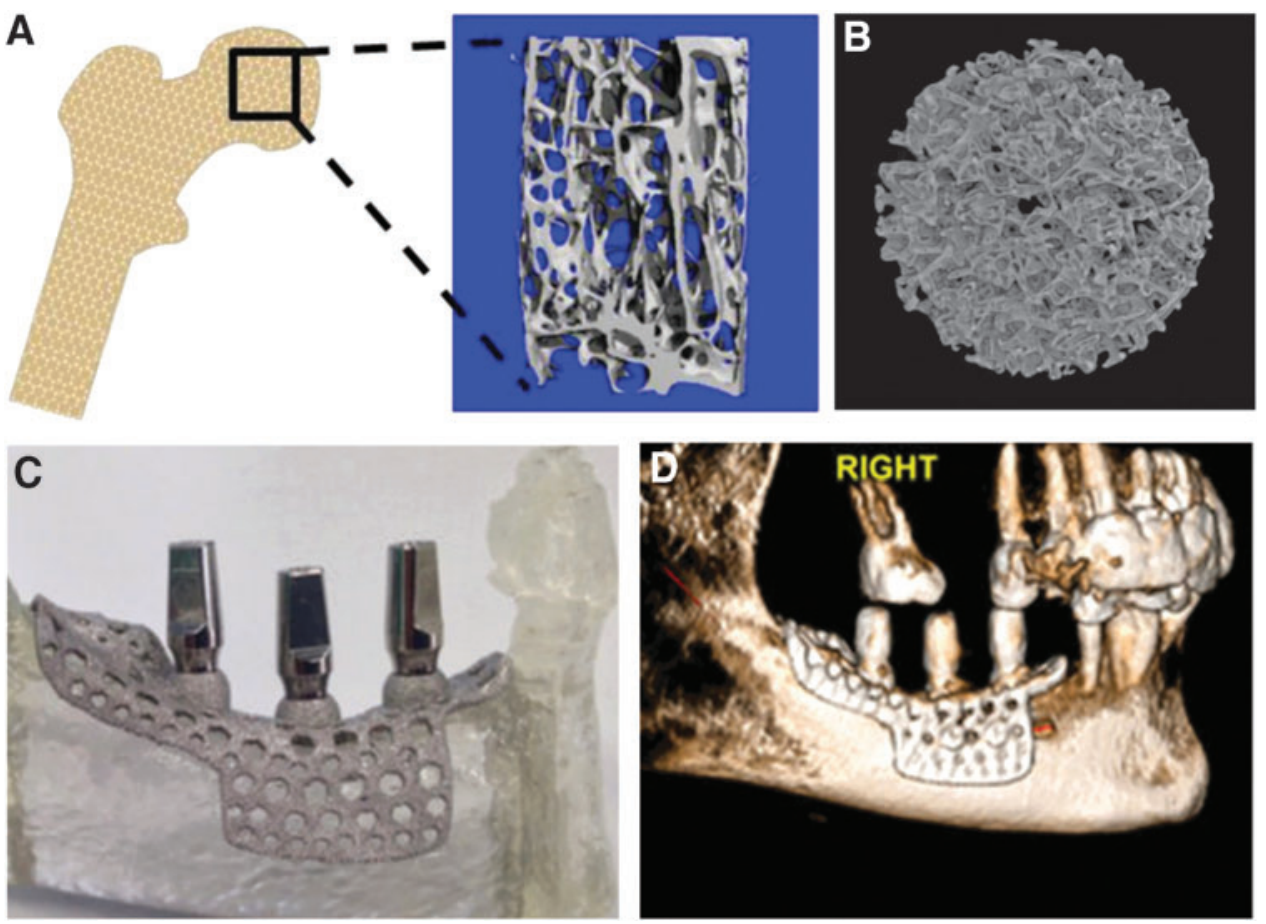

with the same method, NHOsts were less sensitive to changes in the percent porosity compared with MG63 cells. $^{68}$ This corroborates other studies on hydroxyapatite scaffolds indicating that percent porosity may matter less than pore distribution, size, and surface parameters. ${ }^{69}$ Further in vivo studies in the rat calvaria have shown that $3 \mathrm{D}$ printed Ti-6Al-4V implants with biologically inspired porosity have the ability to induce vertical bone regeneration. ${ }^{70}$ These studies showcase the importance of using biologically inspired porosity with the potential to be personalized to the patient, rather than predefined porosity with a homogenous pore distribution. Additional work has been conducted on 3D printing of PLGA, PCL, and hydroxyapatite scaffolds for bone tissue engineering, as well as patient-specific printing of Ti-6Al-4V for dental implants (Fig. 4C, D) ${ }^{71}$

One of the challenges of cartilage regeneration is that the tissue itself is heterogeneous, with gradients in cells, matrix composition, and mechanical properties. Biofabrication or bioprinting methods that combine additive manufacturing of both the scaffold material and biological factors or cells are attractive for their ability to provide spatial and temporal control within a single manufacturing step. ${ }^{72-74}$ Bioprinting using ECM components and cells is a promising strategy for providing an appropriate environment for cartilage regeneration that mimics the native tissue. ${ }^{75}$ However, unlike sintering, which requires high temperature or energy to bond a bed of powder, most biofabrication processes are low in temperature and extrusion-based so as to not harm the biological components of the scaffold. Extrusion and inkjet printing remain the most popular methods for biofabrication, $^{60}$ although these methods are limited by their material specifications and lower resolution.

Because bulk mechanical properties of layer-by-layer sintered powders are different than that of cast or forged metals, postprocessing treatments are necessary for ensuring mechanical compatibility and functionality with the host tissue. ${ }^{76}$ Studies have shown dramatic improvements in elongation at failure and yield strength for additively manufactured Ti-6Al-4V parts after thermal postprocessing. ${ }^{77}$ In addition, build orientation should also be considered for optimizing mechanical properties of additively manufactured Ti-6Al-4V. ${ }^{78}$

Endochondral bone formation, requiring first the formation of cartilage before bone, is favored when mechanical forces are present at the site. ${ }^{79}$ Scaffolds for cartilage regeneration can use this to their advantage by incorporating dynamic mechanical properties into their design. While the magnitude of loading for bone and cartilage are different, the ability for scaffolds to transfer these forces to cells is pertinent for both applications. Particularly for bone, scaffolds with mechanical properties mimicking the host bone are desirable for both osseointegration through endochondral ossification and prevention of stress shielding once osseointegrated.

\section{Surface Roughness}

While scaffold macrostructure and geometry can be easily customized and influence later stages of tissue regeneration, micro- and nanoscale features can more directly impact biological response. Surface microroughness of solid orthopedic implants has been shown to enhance osseointegration in comparison to smooth implants, which tend to favor soft tissue formation. ${ }^{80}$ Recent studies suggest that surface microroughness is just as important for osseointegration and bone regulation in porous scaffolds. ${ }^{66,81}$ From studies of osteoblasts on rough titanium surfaces, we know that microroughness alone is able to alter cell morphology and induce osteoblastic differentiation. ${ }^{82}$ This occurs based solely on the surface roughness, without the use of exogenous factors, and through a different mechanistic pathway than the canonical Wnt3A pathway. ${ }^{83}$ The Wnt5A pathway 
has been implicated in osteoblast response to surface roughness, which is also integrated with integrin signaling. ${ }^{84}$ Specifically, integrin $\alpha 2 \beta 1$ has been found responsible for osteoblast response to titanium surface microtopography, ${ }^{85}$ which is important for understanding both the direct and indirect effects of surface roughness on bone growth. A recently published review highlights the role surface roughness on mesenchymal stem cell (MSC) response on bone interfacing titanium implant surfaces. ${ }^{86}$ Beyond cell response, surface roughness may also provide structural nucleation sites for hydroxyapatite precipitation. ${ }^{87}$

In addition to microscale topography, the nanotopography of biomaterials can shape stem cell destiny, and may affect the adhesion and differentiation of stem cells. ${ }^{88,89}$ Oxidized nanostructures on titanium are typically achieved through thermal or electrochemical treatments. Thermal and hydrothermal treatments occur at high temperatures, although at longer time scales spontaneous nanostructures have formed on pure titanium surfaces stored in saline at room temperature. $^{90}$ Additively manufactured Ti-6Al-4V scaffolds anodized to produce $70 \mathrm{~nm}$ diameter nanotubes showed significantly greater new bone volume compared with scaffolds without surface processing. ${ }^{91}$ Acid etching followed by treatment with $\mathrm{H}_{2} \mathrm{O}_{2} / \mathrm{NaOH}$ and pickling can also generate a combined micro-/nanotopography on additively manufactured $3 \mathrm{D}$ Ti6Al-4V scaffolds. ${ }^{66}$

More recently, the addition of nanoroughness to microroughness to create a hierarchical surface topography has become attractive for increasing biological response on titanium surfaces. ${ }^{92}$ This also mimics the natural structure of native bone. Individual hydroxyapatite plates are $25-50 \mathrm{~nm}$ in diameter, and collagen molecules are $1.23 \mathrm{~nm}$ in diameter and $300 \mathrm{~nm}$ in length. ${ }^{93}$ Although cell response to nanotopography is not completely understood, emerging reports suggest that it may also occur through a different pathway than response to microtopography. ${ }^{94}$ The nanotopographical features of biomaterials have been identified as able to influence cell behaviors by affecting the conformation of integrin-binding proteins, changing the availability of binding sites, and modifying integrin signaling. ${ }^{95}$ Evaluation of MSC proliferation and osteogenic differentiation on nonwoven and patterned poly-Llactic acid (PLLA) nanofibrous meshes fabricated by electrospinning showed that nanofibrous meshes were able to direct cell morphology through their nanotopographical features and nanofiber orientation. A nanotextured surface presented by patterned nanofibrous meshes provided a more effective microenvironment for osteoblastic differentiation of MSCs when compared with nonwoven nanofibrous meshes. This topography-driven commitment was found to be related in part to the RhoA-ERK signaling pathway, as well as the regulation of Runx 2 gene expression. ${ }^{96}$

Surface microroughness can be difficult to achieve homogeneously across surfaces of a 3D scaffold. Physical lineof-sight methods such as grit blasting or spray coating are not always able to reach internal pore surfaces. ${ }^{66,97}$ Even clinically used coatings such as hydroxyapatite are not always stable, and can lead to mechanical failure after repeated loading. ${ }^{98}$ Etching and oxidation remain two surface processing methods that, when performed in a controlled environment, can affect all surfaces of a 3D scaffold. While alkali treatments can alter the mechanical properties of titanium scaffolds, acid etching is used for surface roughness of implants that are currently in clinical use. ${ }^{81}$ For many scaffolds, a combination of acid etching and direct surface oxidation has been used to induce hierarchical micro- and nanoroughness. Studies have shown that osteoblasts tend to favor the sharp peaks generated by acid treatment, while a superimposed oxidized nanoroughness can enhance this response. $^{92}$

\section{Surface Functionalization and Exogenous Factors}

Currently, bone tissue engineering involves use of a bone graft either from a cadaver (allograft) or directly from the patient (autograft). Allografts can cause inflammation and potential host rejection, but moderate applications of current formulations have shown positive results. ${ }^{99-101}$ Autografts are considered the most popular and preferred bone graft; however, they often require an additional surgery with potential complications, and are limited by the amount that is available in a given patient. ${ }^{102}$ Therefore, natural and synthetic bone grafting substitutes have become an alternative method for regenerating bone. ${ }^{102,103}$ For large defect areas, a structural scaffold may not be enough to support complete regeneration. In these cases, exogenous factors and peptides can be functionalized to the scaffold surface to enhance regeneration. Indeed, functionalized growth factors on scaffold surfaces may present a more controlled mode of delivery compared with soluble delivery. It is possible to design scaffolds that present more than one factor and to control their spatial and temporal delivery. For example, incorporating both VEGF to stimulate vasculogenesis and bone morphogenetic protein 2 (BMP2) to stimulate osteogenesis in layer-by-layer assembled polyelectrolyte films increased bone formation to $33 \%$ compared with films with BMP2 alone. ${ }^{104}$ Use of functionalized scaffolds may better mimic the natural presentation of growth factors by the ECM, in contrast to soluble factors secreted by cells. Tissue engineering strategies should also consider endogenous growth factor presentation when optimizing local factor delivery. ${ }^{105}$

Tissue engineering has evolved to include the combination of a scaffold matrix with cells and biologically active molecules to form a construct that promotes tissue repair and regeneration. These three basic components work together to establish an appropriate niche for tissue regeneration. ${ }^{106}$ While scaffolds and biomaterials were originally designed as a substitute to organs, scientists are starting to design scaffolds that integrate with and enhance the natural regenerative processes of the human body. Recent work suggests that anatomically correct scaffolds combined with growth factor delivery can regenerate articular cartilage without cells. ${ }^{107}$ A major challenge for establishing this niche is to recruit and facilitate cell differentiation at the site of repair. Often the number of endogenous cells capable of migrating onto a scaffold and differentiating into the desired tissue is not sufficient for this approach. Current work has focused on the use of autologous cells that are harvested from the patient, expanded in culture, and finally implanted back into the patient, although complications can result at each step. ${ }^{108,109}$

Instead of implanting cells with the scaffold, an alternate strategy is to recruit MSCs directly to the site after implantation. Arginine-glycine-aspartic acid (RGD), a peptide derived from fibronectin in ECM, is best known for enhancing 
A

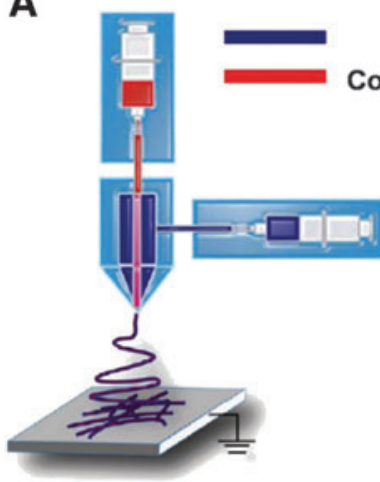

PCL Shell

Core containing rhTGF- $\beta 1$

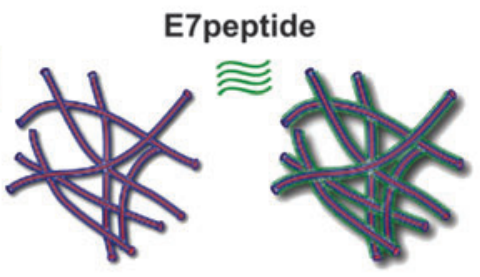

B

B
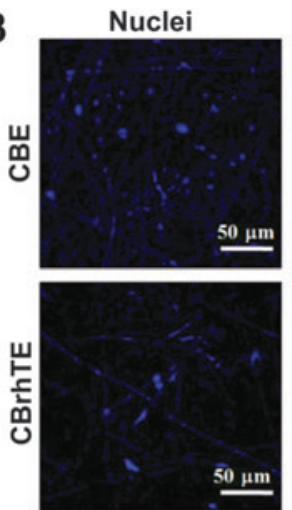
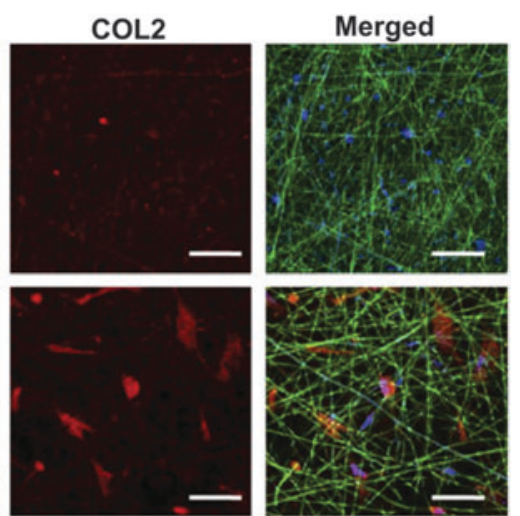

FIG. 5. Electrospun coaxial PCL fibers with rhTGF-b1 were surface modified with an MSC homing E7 peptide (A). BMSCs were attached on both CBE and CBrhTE scaffolds with E7, but produced more COL2 on CBrhTE scaffolds with release of rhTGF-b1 (B). MSC, mesenchymal stem cell; BMSCs, bone marrow-derived stem cells.

cell adhesion on synthetic material surfaces. ${ }^{110-113}$ The MSChoming peptide, E7, has been developed using phage display and conjugated to PCL electrospun meshes, which have shown the ability to attract MSCs in vivo. In addition, the E7-conjugated PCL electrospun meshes are specific for MSC recruitment, compared with the RGD-conjugated PCL electrospun meshes that attract multiple cell types. ${ }^{41}$ These approaches recruit the body's existing population of stem cells, which is attractive for saving time and decreasing immune response.

Other scaffolds have used chemotactic and peptide functionalization for cell homing. ${ }^{107,114-116}$ Modification of coaxial PCL electrospun scaffold with codelivery of E7 and recombinant human transforming growth factor beta-1 (rhTGF- $\beta 1$ ) for cartilage regeneration has also shown success in targeting MSCs in tissues of interest with high efficiency (Fig. 5). ${ }^{117}$ The scaffolds not only enhanced bone marrow-derived MSC adhesion and growth, but also promoted their chondrogenic differentiation in vitro. This was due to the combination of nanoscale fibers that mimicked the physical structure of the $\mathrm{ECM}^{118}$ and supported MSC growth; recruitment of MSCs by E7 on the PCL shell of the coaxial fibers, and controlled release of rhTGF- $\beta 1$ encapsulated in the core of coaxial fibers to MSC chondrogenic differentiation.

E7 has been conjugated onto the surface of DBM and delivered within a chitosan hydrogel as a single functional biomaterial for in vivo cartilage repair with a one-step surgical procedure (Fig. 6). ${ }^{19}$ The biofunctional scaffold was able to sustain a large number of cells within the microfracture clot during the sol-gel phase transition of chitosan, with mechanical support provided by the solid matrix to enable neocartilage formation and maturation. Additionally, conjugation of the affinity peptide to the scaffold facilitated the recruitment and homing of additional MSCs from the subchondral marrow and peripheral blood to enhance cartilage regeneration and integration within the host tissue.

rh-BMP2 and BMP7 are approved for clinical use in certain spinal, long bone, and maxillofacial procedures, and have shown positive results when used with scaffolds in vitro. ${ }^{71,120-124} \mathrm{Up}$ to $85 \%$ of BMP use is off label. ${ }^{125}$ Studies show that BMPs can be detrimental when used in
FIG. 6. MSC affinity peptide functionalized to surface of biphasic DBM scaffolds with chitosan (A). Manufactured scaffolds (B) possessed a rough topography and porosity $(\mathbf{C})$ and were able to attract cells to cartilage when implanted (D).
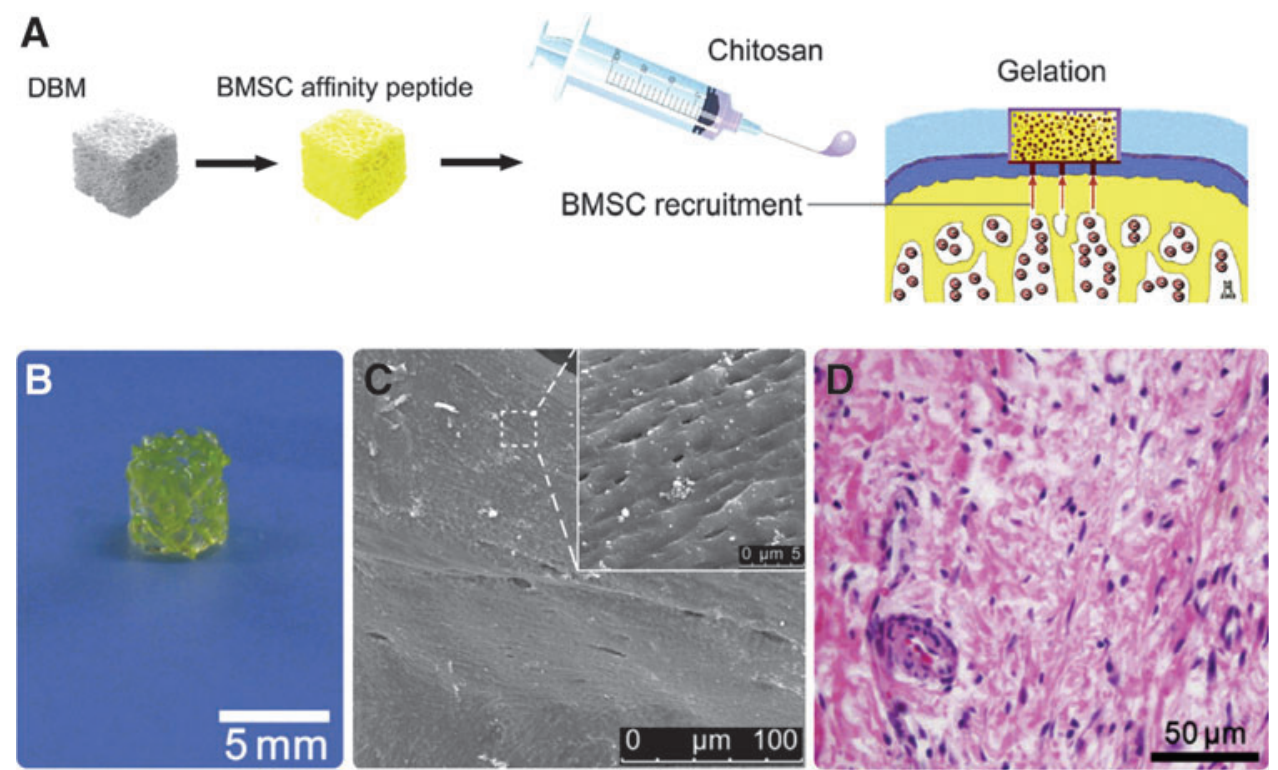
high concentrations or for off-label indications. ${ }^{126}$ In vitro studies show that BMP2 induces apoptosis in a cell-typedependent manner, with osteoblasts more sensitive to increasing concentrations of BMP2 compared with MSCs. ${ }^{127}$ Additionally, it is challenging to evaluate growth factor release profiles after implantation, especially for scaffolds with multiple growth factors. ${ }^{128}$ Therefore, care should be taken to use the appropriate dose of BMP, especially for non-FDAapproved indications. Other growth factors commonly used for bone regeneration include VEGF, fibroblast growth factor 2 (FGFs), and TGF- $\beta 1$. While trials are ongoing, none of these have been clinically approved for use. ${ }^{129,130}$

For cartilage regeneration, efforts have focused on increasing matrix production. Microfracture procedures are still commonly performed, but the resulting fibrocartilage does not have the properties of native cartilage and can deteriorate over time. ${ }^{131}$ While autologous cells have become more popular in cartilage repair compared with bone repair, biomaterials are still being studied to facilitate tissue regeneration. Degradable hydrogels are preferable for this application. Recent work functionalizing degradable poly(ethyleneglycol) hydrogels with TGF- $\beta 1$ and delivered with a mixed population of chondrocytes and MSCs shows promising results for new cartilage growth and remodeling. ${ }^{132}$

Nanoparticles developed for bone tissue engineering can be used to deliver drugs, vaccines, and growth factors with tunable release profiles. ${ }^{133}$ Carrier particles include bioglass, PLLA, hydroxyapatite, and cobalt ferrite, where the molecule of interest is conjugated to the surface of the nanoparticle for delivery. Additional work shows that electrospun composite scaffolds sprayed with hydroxyapatite nanoparticles enhanced mineralization and alkaline phosphatase-specific activity of human fetal osteoblasts compared with tissue culture polystyrene; scaffolds without these nanoparticles did not perform statistically better than the control. ${ }^{134}$ To monitor new bone growth and scaffold integration, a variety of noninvasive imaging and mechanical techniques have been introduced. Lanthanide apatite particles with fluorescence have been used to distinguish new bone tissue from the implanted scaffold, which can be tracked noninvasively over time (Fig. 7). ${ }^{135}$

In contrast to nanoparticles, larger microbeads can be used to encapsulate and deliver cells to bone and cartilage requiring regeneration. For targeted cell delivery, carriers must retain cells at the intended site and ensure cell viability, and, for stem cells, maintain a certain state of differentiation or stemness. MSCs are attractive for both bone and cartilage regeneration. In vitro culture of chondrocytes has proved challenging, and cell therapies based on chondrocyte delivery fail to regenerate cartilage due to dedifferentiation of cells during culture expansion. ${ }^{136}$ Alginate microbeads serve as one delivery mechanism for MSCs; the microbeads retain cells at the implant site, and when alginate lyase is incorporated, enable release of cells through controlled degradation of the alginate. $^{137}$ Using microextrusion, alginate hydrogels have been shown to maintain cell viability in culture up to 2 weeks after manufacturing. ${ }^{138}$ Larger alginate hydrogel scaffolds have also been printed with separate compartments for chondrocyte and progenitor cell delivery. ${ }^{139}$

An interesting aspect to consider in the development of "smart" biomaterials is the ability to modulate the effects of functionalized molecules on the scaffold surface. Degradable scaffolds must have consistent and controllable degradation rates, especially if release of growth factors occurs with degradation. One method for achieving this is by including enzyme-sensitive regions in the polymer. The scaffolds also need to ensure that they maintain sufficient mechanical properties conducive to cell growth and ECM deposition during degradation. ${ }^{26,140}$ As an example, fast degradation of scaffolds containing Mg2+ may cause pockets to form that may negatively impact healing. Thus, alloying elements and scaffold materials must be chosen and designed with care so that they continue to serve their purpose throughout the lifetime of the scaffold. Even nondegradable scaffolds should consider stability of functionalized factors, coatings, or surface nanofeatures.

\section{Biological Evaluation}

New manufacturing approaches for tissue engineering scaffolds offer increased structural flexibility and resolution. However, challenges still exist in commercializing these materials for clinical use. Functionalized scaffolds or those with cells must be properly packaged, stored, and implanted correctly by the physician. ${ }^{141}$ Quality control that fails at
A

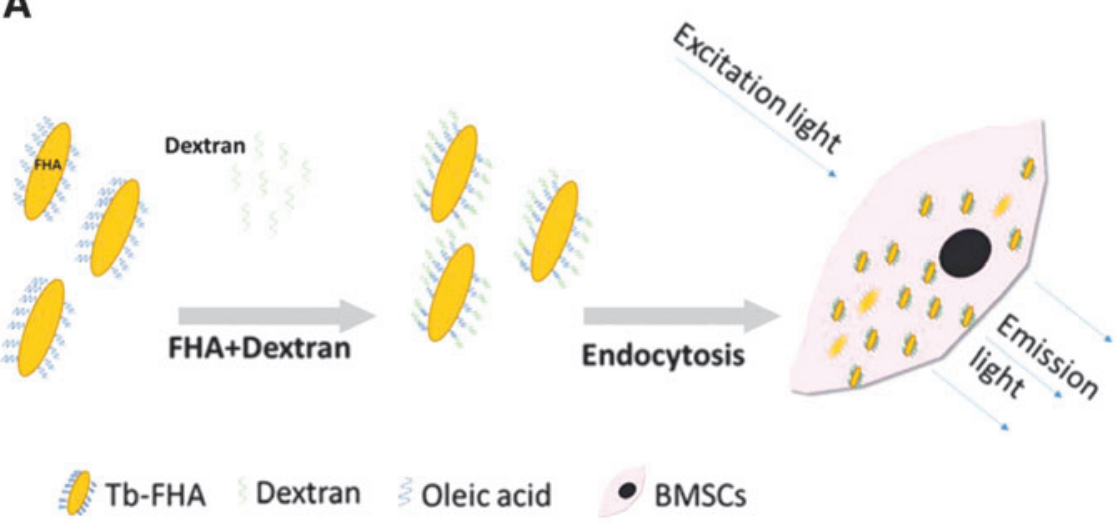

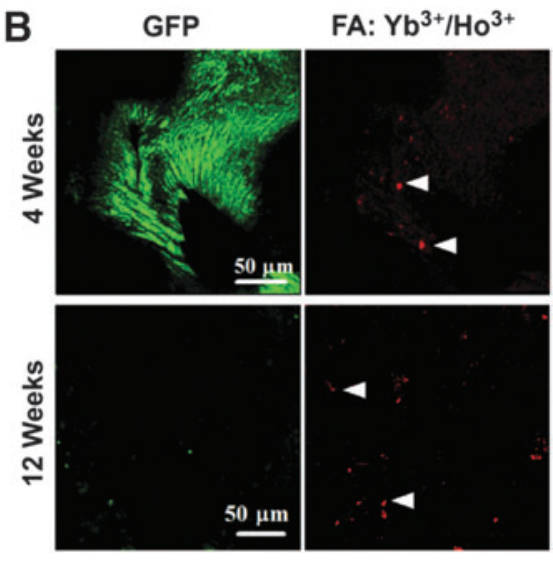

FIG. 7. Fluorapatite nanorods doped with lanthanides can be endocytosed by and used to track cells over time (A). GFPlabeled BMSCs on DCCBM scaffolds in nude mice with $50 \mu \mathrm{g} / \mathrm{mL} \mathrm{FA:Yb3+/Ho3+} \mathrm{after} 4$ (top) and 12 (bottom) weeks after transplantation (B). Two photon imaging shows that while GFP intensity decreased with time, upconversion nanoparticles retained a strong fluorescent signal. White triangles indicate successful uptake of crystals by BMSCs. 
any of these steps can lead to catastrophic consequences. To reduce infection in implanted scaffolds, the addition of silver, copper, and zinc ions to metallic implant scaffolds have shown favorable antibacterial effects. ${ }^{142}$ These can be incorporated through the native oxide layer, through deposition or as part of the alloy before fabrication. Graphene has also been shown to reduce biofilm formation when functionalized on scaffold surfaces. ${ }^{143}$

Preliminary in vitro investigations on biological response to scaffolds often use immortalized cell lines or mature primary cells. There is an increasing number of studies that choose instead to focus on the response of MSCs to the biomaterial surface. Because MSCs are one of the first cells to the wound site and have the potential to differentiate into osteoblasts, chondrocytes, and fibroblasts, altering their fate can lead to successful integration or to fibrous capsule encapsulation and ultimately scaffold failure. Studies have also shown the ability of MSCs to distally affect cells near the implant through release of growth factors. However, the use of MSCs, and in fact many primary cells, can result in differential responses based on donor gender, age, and health. Osteoblasts from a female donor, for example, secrete lower levels of osteocalcin compared with osteoblasts from a male donor. ${ }^{144}$ Osteoblasts from 11-month-old mice displayed a reduced response to titanium surface microroughness and $1 \alpha, 25(\mathrm{OH})_{2} \mathrm{D}_{3}$ compared with osteoblasts isolated from 1-month-old mice. ${ }^{145}$ Differences exist even among the source of MSCs. Bone marrow-derived MSCs had higher proliferation and matrix production on scaffolds used for cartilage repair compared with adiposederived MSCs. ${ }^{146}$ Although the use of primary cells is more clinically relevant, it can be cost prohibitive to screen across multiple donors to account for variation during preliminary biomaterial evaluation. Primary cells also have a finite number of passages, and especially in the case of chondrocytes, can lose phenotype very quickly when cultured in vitro. ${ }^{137,144,147}$

Small animal models are convenient for in vivo screening of orthopedic scaffolds due to their cost convenience and short lifespans, but they only partially physiologically mimic the human musculoskeletal system. Therefore, larger animals are preferable for evaluating scaffolds on a larger spatial and longer temporal scale closer to that of humans. Larger animals, such as primates, dogs, sheep, and pigs possess bone architecture more comparable to that of humans. Small rodents, for example, do not have fully developed Haversian systems, an important component of human cortical bone. ${ }^{148}$ In addition, larger animals may have other properties similar to humans that can affect bone regeneration. An increasing number of studies have focused on sex differences and the role of estrogen deficiency or supplementation on bone regeneration. ${ }^{149}$ For these studies, it is important to choose an animal model that mimics an estrous cycle similar to humans. While many models for osteoarthritis exist for mice and rats, they do not recapitulate all the systemic effects of the disease as observed in humans. ${ }^{150,151}$ In contrast, horses have naturally occurring osteoarthritis that may be a more suitable model for regenerative scaffold therapies. ${ }^{152}$

Once an animal has been chosen, the implantation site must also be considered. Studies have indicated higher bone to implant contact and osseointegration of implants placed in cortical bone compared with trabecular bone. ${ }^{153} \mathrm{In} \mathrm{hu}-$ mans, it takes 3-6 months for trabecular bone to remodel, and $6-12$ months for cortical bone to remodel. ${ }^{154}$ When evaluating bone or cartilage regeneration, it is also important to establish a critically sized defect for each animal model. Not only is the defect size important, but appropriate negative controls that are currently available should also be used for comparison, not just a void space. ${ }^{155}$

Advanced as biofabrication methods are, experts do not expect a musculoskeletal tissue-engineered substitute to be available clinically anytime in the immediate future. Biomaterial design today faces challenges in vascularization and necrosis, the same problems that the biomedical community has faced over the past 50 years. ${ }^{60}$ Additional challenges in maintaining cell viability require continued optimization of manufacturing temperature, mechanical extrusion strain, and the use of crosslinking agents. ${ }^{74,156,157}$ In addition, standards are still lacking for characterization of materials, degradation products, and evaluation of tissue regeneration after implantation. ${ }^{86,158}$ Even biomaterials that are engineered in the laboratory and work in in vitro and in vivo systems do not always translate to successful clinical use. The term "regenerative medicine" has been defined to include both cell therapy and regenerative surgery, or a combination of biology and human skill. ${ }^{159}$ Thus, it is imperative that scientists, engineers, and orthopedic surgeons work collaboratively when developing new materials for bone and cartilage regeneration.

Although over 1400 articles have been published between 2003 and 2013 on "smart" scaffolds for bone tissue engineering, there were only 23 clinical trials evaluating the use of bone scaffolds. ${ }^{160,161}$ One reason for this dichotomy is the continued controversy over classification of these scaffolds by the United States Food and Drug Administration (FDA). Currently, the FDA provides three types of regulatory pathways for new products entering the market: biologic, device, or drug, and when used together, as a combination product. Scaffolds as a structural support, similar to orthopedic implants, are most easily regulated through the device pathway, which requires a $510 \mathrm{~K}$ clearance if the manufacturer can claim similarity to a product previously approved. As scaffolds for tissue engineering become more advanced, they may require a different regulatory pathway for approval. A clear pathway for evaluating and regulating safety and effectiveness of scaffolds will also advance clinical progress in bone and cartilage tissue engineering.

\section{Conclusion}

Many advances have been made in scaffold design and manufacturing for bone and cartilage tissue engineering. Strategies in scaffold design now focus on recruiting and differentiating MSC populations at the site of regeneration. New manufacturing techniques, including additive manufacturing, are paving the way to personalized materials. Processing at the macro-, micro-, and nanoscales also contribute to biological response and clinical success. Finally, we see an integration of functional scaffold design and the innate regeneration potential of patients, rather than relying on the material alone. While still in development, these materials show great promise for clinical translation within the next decade.

\section{Acknowledgments}

This work is supported by the National Basic Research Program of China (2012CB933903), National Key Research and Development Program of China (Project No. 
2016YFC1101301), and National Institutes of Health grant AR052102. AC is a recipient of the National Foundation Graduate Research Fellowship and the Whitaker International Fellowship.

\section{Disclosure Statement}

No competing financial interests exist.

\section{References}

1. Kurtz, S., Ong, K., Lau, E., Mowat, F., and Halpern, M. Projections of Primary and Revision Hip and Knee Arthroplasty in the United States from 2005 to 2030. J Bone Joint Surg Am 89, 780, 2007.

2. Hutmacher, D.W. Scaffolds in tissue engineering bone and cartilage. Biomaterials 21, 2529, 2000.

3. Bourke, V.A., Watchman, C.J., Reith, J.D., Jorgensen, M.L., Dieudonnè, A., and Bolch, W.E. Spatial gradients of blood vessels and hematopoietic stem and progenitor cells within the marrow cavities of the human skeleton. Blood 114, 4077, 2009.

4. Zhang, L., Hu, J., and Athanasiou, K.A. The role of tissue engineering in articular cartilage repair and regeneration. Crit Rev Biomed Eng 37, 1, 2009.

5. Hattori, T., Müller, C., Gebhard, S., et al. SOX9 is a major negative regulator of cartilage vascularization, bone marrow formation and endochondral ossification. Development 137, 901, 2010.

6. Marsell, R., and Einhorn, T.A. The biology of fracture healing. Injury 42, 551, 2011.

7. O'Driscoll, S.W. Current concepts review-The healing and regeneration of articular cartilage. J Bone Joint Surg 80, 1795, 1998.

8. Gentile, P., Chiono, V., Carmagnola, I., and Hatton, P.V. An overview of poly(lactic-co-glycolic) acid (PLGA)based biomaterials for bone tissue engineering. Int J Mol Sci 15, 3640, 2014.

9. Middleton, J.C., and Tipton, A.J. Synthetic biodegradable polymers as orthopedic devices. Biomaterials 21, 2335, 2000.

10. Yilgor, I., Bilgin, S., Isik, M., and Yilgor, E. Tunable Wetting of Polymer Surfaces. Langmuir 28, 14808, 2012.

11. Ulery, B.D., Nair, L.S., and Laurencin, C.T. Biomedical applications of biodegradable polymers. J Polym Sci B Polym Phys 49, 832, 2011.

12. Neuss, S., Blomenkamp, I., Stainforth, R., et al. The use of a shape-memory poly( $\varepsilon$-caprolactone)dimethacrylate network as a tissue engineering scaffold. Biomaterials 30, 1697, 2009.

13. Lee, E.M., Smith, K., Gall, K., Boyan, B.D., and Schwartz, $\mathrm{Z}$. Change in surface roughness by dynamic shape-memory acrylate networks enhances osteoblast differentiation. Biomaterials 110, 34, 2016.

14. Wang, Y., Bella, E., Lee, C.S., et al. The synergistic effects of 3-D porous silk fibroin matrix scaffold properties and hydrodynamic environment in cartilage tissue regeneration. Biomaterials 31, 4672, 2010.

15. Wang, Y., Kim, H.J., Vunjak-Novakovic, G., and Kaplan, D.L. Stem cell-based tissue engineering with silk biomaterials. Biomaterials 27, 6064, 2006.

16. Shi, W., Sun, M., Hu, X., et al. Structurally and functionally optimized silk-fibroin-gelatin scaffold using 3D printing to repair cartilage injury in vitro and in vivo. Adv Mater 29, 2017. [Epub ahead of print]; DOI: 10.1002/adma.201701089
17. Kim, U.J., Park, J., Li, C., Jin, H.J., Valluzzi, R., and Kaplan, D.L. Structure and properties of silk hydrogels. Biomacromolecules 5, 786, 2004.

18. Nazarov, R., Jin, H.J., and Kaplan, D.L. Porous 3-D scaffolds from regenerated silk fibroin. Biomacromolecules 5, 718, 2004.

19. Cheng, C.W., Solorio, L.D., and Alsberg, E. Decellularized tissue and cell-derived extracellular matrices as scaffolds for orthopaedic tissue engineering. Biotechnol Adv 32, 462, 2014.

20. McClure, M.J., Cohen, D.J., Ramey, A.N., et al. Decellularized muscle supports new muscle fibers and improves function following volumetric injury. Tissue Eng A 24, 1228, 2018.

21. Eggli, P.S., Muller, W., and Schenk, R.K. Porous hydroxyapatite and tricalcium phosphate cylinders with two different pore size ranges implanted in the cancellous bone of rabbits. A comparative histomorphometric and histologic study of bony ingrowth and implant substitution. Clin Orthop Relat Res 232, 127, 1988.

22. Zhao, G., Raines, A.L., Wieland, M., Schwartz, Z., and Boyan, B.D. Requirement for both micron and submicron scale structure for synergistic responses of osteoblasts to substrate surface energy and topography. Biomaterials 28, 2821, 2007.

23. Rahaman, M.N., Day, D.E., Bal, B.S., et al. Bioactive glass in tissue engineering. Acta Biomater 7, 2355, 2011.

24. Hollister, S.J. Porous scaffold design for tissue engineering. Nat Mater 4, 518, 2005.

25. Murphy, C.M., and O'Brien, F.J. Understanding the effect of mean pore size on cell activity in collagenglycosaminoglycan scaffolds. Cell Adh Migr 4, 377, 2010.

26. Karageorgiou, V., and Kaplan, D. Porosity of 3D biomaterial scaffolds and osteogenesis. Biomaterials 26, 5474, 2005.

27. Whang, K., Goldstick, T.K., and Healy, K.E. A biodegradable polymer scaffold for delivery of osteotropic factors. Biomaterials 21, 2545, 2000.

28. Whang, K., Healy, K.E., Elenz, D.R., et al. Engineering bone regeneration with bioabsorbable scaffolds with novel microarchitecture. Tissue Eng 5, 35, 1999.

29. Kim, J., and Ma, T. Bioreactor strategy in bone tissue engineering: pre-culture and osteogenic differentiation under two flow configurations. Tissue Eng A 18, 2354, 2012.

30. Shimko, D.A., Shimko, V.F., Sander, E.A., Dickson, K.F., and Nauman, E.A. Effect of porosity on the fluid flow characteristics and mechanical properties of tantalum scaffolds. J Biomed Mater Res B Appl Biomater 73, 315, 2005.

31. Perez, R.A., and Mestres, G. Role of pore size and morphology in musculo-skeletal tissue regeneration. Mater Sci Eng C Mater Biol Appl 61, 922, 2016.

32. Wang, X., Schwartz, Z., Gittens, R.A., et al. Role of integrin $\alpha 2 \beta 1$ in mediating osteoblastic differentiation on three-dimensional titanium scaffolds with submicronscale texture. J Biomed Mater Res A 103, 1907, 2015.

33. Glenn, D.R., Zhang, H., Kasthuri, N., et al. Correlative light and electron microscopy using cathodoluminescence from nanoparticles with distinguishable colours. Sci Rep 2, 865, 2012.

34. Huang, H., Zhang, X., Hu, X., et al. Directing chondrogenic differentiation of mesenchymal stem cells with a solid-supported chitosan thermogel for cartilage tissue engineering. Biomed Mater 9, 035008, 2014. 
35. Cong, Y., Liu, S., and Chen, H. Fabrication of conductive polypyrrole nanofibers by electrospinning. J Nanomater 2013, 6, 2013.

36. Hyzy, S.L., Cheng, A., Cohen, D.J., et al. Novel hydrophilic nanostructured microtexture on direct metal laser sintered Ti-6Al-4V surfaces enhances osteoblast response in vitro and osseointegration in a rabbit model. $\mathrm{J}$ Biomed Mater Res A 104, 2086, 2016.

37. Wang, X., Hao, T., Qu, J., Wang, C., and Chen, H. Synthesis of thermal polymerizable alginate-GMA hydrogel for cell encapsulation. J Nanomater 2015, 8, 2015.

38. Xie, J., Li, X., and Xia, Y. Putting electrospun nanofibers to work for biomedical research. Macromol Rapid Commun 29, 1775, 2008.

39. Liu, W., Thomopoulos, S., and Xia, Y. Electrospun nanofibers for regenerative medicine. Adv Healthc Mater 1, 10, 2012.

40. Liu, W., Yeh, Y.C., Lipner, J., et al. Enhancing the stiffness of electrospun nanofiber scaffolds with a controlled surface coating and mineralization. Langmuir 27, 9088, 2011.

41. Shao, Z., Zhang, X., Pi, Y., et al. Polycaprolactone electrospun mesh conjugated with an MSC affinity peptide for MSC homing in vivo. Biomaterials 33, 3375, 2012.

42. Agarwal, S., Wendorff, J.H., and Greiner, A. Progress in the field of electrospinning for tissue engineering applications. Adv Mater 21, 3343, 2009.

43. Luo, C.J., Nangrejo, M., and Edirisinghe, M. A novel method of selecting solvents for polymer electrospinning. Polymer 51, 1654, 2010.

44. Matthews, J.A., Wnek, G.E., Simpson, D.G., and Bowlin, G.L. Electrospinning of collagen nanofibers. Biomacromolecules 3, 232, 2002.

45. Jin, H.J., Chen, J., Karageorgiou, V., Altman, G.H., and Kaplan, D.L. Human bone marrow stromal cell responses on electrospun silk fibroin mats. Biomaterials 25, 1039, 2004.

46. Matthews, J.A., Boland, E.D., Wnek, G.E., Simpson, D.G., and Bowlin, G.L. Electrospinning of collagen type II: a feasibility study. J Bioact Compat Polym 18, 125, 2003.

47. Li, X., Xie, J., Lipner, J., Yuan, X., Thomopoulos, S., and Xia, Y. Nanofiber scaffolds with gradations in mineral content for mimicking the tendon-to-bone insertion site. Nano Lett 9, 2763, 2009.

48. Liu, W., Lipner, J., Moran, C.H., et al. Nanofibers: generation of electrospun nanofibers with controllable degrees of crimping through a simple, plasticizer-based treatment. Adv Mater 27, 2583, 2015.

49. Liu, W., Lipner, J., Xie, J., Manning, C.N., Thomopoulos, S., and Xia, Y. Nanofiber scaffolds with gradients in mineral content for spatial control of osteogenesis. Appl Mater Interfaces 6, 2842, 2014.

50. $\mathrm{Xu}, \mathrm{S}$., Deng, L., Zhang, J., et al. Composites of electrospun-fibers and hydrogels: a potential solution to current challenges in biological and biomedical field. $\mathrm{J}$ Biomed Mater Res B Appl Biomater 104, 640, 2016.

51. Li, W.J., Laurencin, C.T., Caterson, E.J., Tuan, R.S., and Ko, F.K. Electrospun nanofibrous structure: a novel scaffold for tissue engineering. J Biomed Mater Res 60, 613, 2002.

52. Allison, C.B., and Rocky, S.T. Fiber diameter and seeding density influence chondrogenic differentiation of mesenchymal stem cells seeded on electrospun poly( $\varepsilon$-caprolactone) scaffolds. Biomed Mater (Bristol, England) 10, 015018, 2015.

53. Eyre, D.R., Weis, M.A., and Wu, J.J. Articular cartilage collagen: an irreplaceable framework? Eur Cell Mater 12, 57, 2006.

54. Zhang, Y., Venugopal, J.R., El-Turki, A., Ramakrishna, S., Su, B., and Lim, C.T. Electrospun biomimetic nanocomposite nanofibers of hydroxyapatite/chitosan for bone tissue engineering. Biomaterials 29, 4314, 2008.

55. Wang, X., Zhu, J., Yin, L., et al. Fabrication of electrospun silica-titania nanofibers with different silica content and evaluation of the morphology and osteoinductive properties. J Biomed Mater Res A 100, 3511, 2012.

56. Wang, X., Gittens, R.A., Song, R., et al. Effects of structural properties of electrospun $\mathrm{TiO} 2$ nanofiber meshes on their osteogenic potential. Acta Biomater 8, 878, 2012.

57. Sing, S.L., An, J., Yeong, W.Y., and Wiria, F.E. Laser and electron-beam powder-bed additive manufacturing of metallic implants: a review on processes, materials and designs. J Orthop Res 34, 369, 2016.

58. Farré-Guasch, E., Wolff, J., Helder, M.N., Schulten, E.A., Forouzanfar, T., and Klein-Nulend, J. Application of additive manufacturing in oral and maxillofacial surgery. $\mathrm{J}$ Oral Maxillofac Surg 73, 2408, 2015.

59. Henkel, J., Woodruff, M.A., Epari, D.R., et al. Bone regeneration based on tissue engineering conceptions - A 21st century perspective. Bone Res 1, 216, 2013.

60. Tang, D., Tare, R.S., Yang, L.Y., Williams, D.F., Ou, K.L., and Oreffo, R.O. Biofabrication of bone tissue: approaches, challenges and translation for bone regeneration. Biomaterials 83, 363, 2016.

61. Amini, A.R., Laurencin, C.T., and Nukavarapu, S.P. Bone tissue engineering: recent advances and challenges. Crit Rev Biomed Eng 40, 363, 2012.

62. Hutmacher, D.W., and Cool, S. Concepts of scaffoldbased tissue engineering-the rationale to use solid freeform fabrication techniques. J Cell Mol Med 11, 654, 2007.

63. Nava, M.M., Draghi, L., Giordano, C., and Pietrabissa, R. The effect of scaffold pore size in cartilage tissue engineering. J Appl Biomater Funct Mater 14, e223, 2016.

64. Sturm, S., Zhou, S., Mai, Y.W., and Li, Q. On stiffness of scaffolds for bone tissue engineering-a numerical study. J Biomech 43, 1738, 2010.

65. Wang, X., Xu, S., Zhou, S., et al. Topological design and additive manufacturing of porous metals for bone scaffolds and orthopaedic implants: a review. Biomaterials 83, 127, 2016.

66. Cheng, A., Humayun, A., Cohen, D.J., Boyan, B.D., and Schwartz, Z. Additively manufactured $3 \mathrm{D}$ porous Ti$6 \mathrm{Al}-4 \mathrm{~V}$ constructs mimic trabecular bone structure and regulate osteoblast proliferation, differentiation and local factor production in a porosity and surface roughness dependent manner. Biofabrication 6, 045007, 2014.

67. Cohen, D.J., Cheng, A., Kahn, A., et al. Novel Osteogenic Ti-6Al-4V device for restoration of dental function in patients with large bone deficiencies: design, development and implementation. Sci Rep 6, 20493, 2016.

68. Cheng, A., Humayun, A., Boyan, B.D., and Schwartz, Z. Enhanced Osteoblast Response to Porosity and Resolution of Additively Manufactured Ti-6Al-4V Constructs with Trabeculae-Inspired Porosity. 3D Print Addit Manuf 3, 10, 2016. 
69. Kasten, P., Beyen, I., Niemeyer, P., Luginbühl, R., Bohner, M., and Richter, W. Porosity and pore size of $\beta$-tricalcium phosphate scaffold can influence protein production and osteogenic differentiation of human mesenchymal stem cells: an in vitro and in vivo study. Acta Biomater 4, 1904, 2008.

70. Cheng, A., Cohen, D.J., Kahn, A., et al. Laser Sintered Porous Ti-6Al-4V Implants Stimulate Vertical Bone Growth. Ann Biomed Eng 45, 2025, 2017.

71. Li, J., He, L., Zhou, C., et al. 3D printing for regenerative medicine: from bench to bedside. MRS Bull 40, 145, 2015.

72. Tasoglu, S., and Demirci, U. Bioprinting for stem cell research. Trends Biotechnol 31, 10, 2013.

73. Bose, S., Vahabzadeh, S., and Bandyopadhyay, A. Bone tissue engineering using 3D printing. Mater Today 16, 496, 2013.

74. Derby, B. Printing and prototyping of tissues and scaffolds. Science 338, 921, 2012.

75. Di Bella, C., Fosang, A., Donati, D.M., Wallace, G.G., and Choong, P.F. 3D bioprinting of cartilage for orthopedic surgeons: reading between the lines. Front Surg 2, 39, 2015.

76. Vrancken, B., Thijs, L., Kruth, J.-P., and Van Humbeeck, J. Heat treatment of Ti6Al4V produced by Selective Laser Melting: microstructure and mechanical properties. J Alloys Compd 541, 177, 2012.

77. Xu, W., Brandt, M., Sun, S., et al. Additive manufacturing of strong and ductile $\mathrm{Ti}-6 \mathrm{Al}-4 \mathrm{~V}$ by selective laser melting via in situ martensite decomposition. Acta Mater 85, 74, 2015.

78. Weißmann, V., Bader, R., Hansmann, H., and Laufer, N. Influence of the structural orientation on the mechanical properties of selective laser melted Ti6Al4V open-porous scaffolds. Mater Des 95, 188, 2016.

79. Dimitriou, R., Tsiridis, E., and Giannoudis, P.V. Current concepts of molecular aspects of bone healing. Injury 36, 1392, 2005.

80. Schwartz, Z., Raz, P., Zhao, G., et al. Effect of micrometer-scale roughness of the surface of Ti6Al4V pedicle screws in vitro and in vivo. J Bone Joint Surg Am 90, 2485, 2008.

81. Amin Yavari, S.A., Ahmadi, S.M., van der Stok, J., et al. Effects of bio-functionalizing surface treatments on the mechanical behavior of open porous titanium biomaterials. J Mech Behav Biomed Mater 36, 109, 2014.

82. Lai, M., Hermann, C.D., Cheng, A., et al. Role of $\alpha 2 \beta 1$ integrins in mediating cell shape on microtextured titanium surfaces. J Biomed Mater Res A 103, 564, 2015.

83. Olivares-Navarrete, R., Hyzy, S.L., Hutton, D.L., et al. Role of non-canonical Wnt signaling in osteoblast maturation on microstructured titanium surfaces. Acta Biomater 7, 2740, 2011.

84. Olivares-Navarrete, R., Hyzy, S.L., Park, J.H., et al. Mediation of osteogenic differentiation of human mesenchymal stem cells on titanium surfaces by a Wnt-integrin feedback loop. Biomaterials 32, 6399, 2011.

85. Olivares-Navarrete, R., Raz, P., Zhao, G., et al. Integrin $\alpha 2 \beta 1$ plays a critical role in osteoblast response to micronscale surface structure and surface energy of titanium substrates. Proc Natl Acad Sci U S A 105, 15767, 2008.

86. Boyan, B.D., Cheng, A., Olivares-Navarrete, R., and Schwartz, Z. Implant surface design regulates mesenchymal stem cell differentiation and maturation. Adv Dent Res 28, 10, 2016.
87. Habibovic, P., and de Groot, K. Osteoinductive biomaterials-properties and relevance in bone repair. J Tissue Eng Regen Med 1, 25, 2007.

88. Zou, X.H., Zhi, Y.L., Chen, X., et al. Mesenchymal stem cell seeded knitted silk sling for the treatment of stress urinary incontinence. Biomaterials 31, 4872, 2010.

89. Dalby, M.J., Gadegaard, N., Tare, R., et al. The control of human mesenchymal cell differentiation using nanoscale symmetry and disorder. Nat Mater 6, 997, 2007.

90. Wennerberg, A., Svanborg, L., Berner, S., and Andersson, M. Spontaneously formed nanostructures on titanium surfaces. Clin Oral Implants Res 0, 1, 2012.

91. Han, T., Chang, B., Ding, X., et al. Improved bone formation and ingrowth for the additively manufactured porous Ti6Al4V bone implants with strontium laden nanotube array coating. RSC Adv 6, 13686, 2016.

92. Gittens, R.A., McLachlan, T., Olivares-Navarrete, R., et al. The effects of combined micron-/submicron-scale surface roughness and nanoscale features on cell proliferation and differentiation. Biomaterials 32, 3395, 2011.

93. Rho, J.Y., Kuhn-Spearing, L., and Zioupos, P. Mechanical properties and the hierarchical structure of bone. Med Eng Phys 20, 92, 1998.

94. Gittens, R.A., Olivares-Navarrete, R., Hyzy, S.L., Sandhage, K.H., Schwartz, Z., and Boyan, B.D. Superposition of nanostructures on microrough titanium-aluminumvanadium alloy surfaces results in an altered integrin expression profile in osteoblasts. Connect Tissue Red 55, 164, 2014.

95. Cavalcanti-Adam, E.A., Aydin, D., Hirschfeld-Warneken, V.C., and Spatz, J.P. Cell adhesion and response to synthetic nanopatterned environments by steering receptor clustering and spatial location. HFSP J 2, 276, 2008.

96. Zhu, J., Cai, Q., Zhang, X., et al. Biological characteristics of mesenchymal stem cells grown on different topographical nanofibrous poly-L-lactide meshes. J Biomed Nanotechnol 9, 1757, 2013.

97. Yang, Y., Kim, K.H., and Ong, J.L. A review on calcium phosphate coatings produced using a sputtering processan alternative to plasma spraying. Biomaterials 26, 327, 2005.

98. Lai, K.A., Shen, W.J., Chen, C.H., Yang, C.Y., Hu, W.P., and Chang, G.L. Failure of hydroxyapatite-coated acetabular cups. Ten-year follow-up of 85 Landos Atoll arthroplasties. J Bone Joint Surg Br 84, 641, 2002.

99. Bauer, T.W., and Muschler, G.F. Bone graft materials: an overview of the basic science. Clin Orthop Relat Res 371, $10,2000$.

100. Schwartz, Z., Goldstein, M., Raviv, E., Hirsch, A., Ranly, D.M., and Boyan, B.D. Clinical evaluation of demineralized bone allograft in a hyaluronic acid carrier for sinus lift augmentation in humans: a computed tomography and histomorphometric study. Clin Oral Implants Res 18, 204, 2007.

101. Boyan, B.D., Ranly, D.M., McMillan, J., Sunwoo, M., Roche, K., and Schwartz, Z. Osteoinductive ability of human allograft formulations. J Periodontol 77, 1555, 2006.

102. García-Gareta, E., Coathup, M.J., and Blunn, G.W. Osteoinduction of bone grafting materials for bone repair and regeneration. Bone 81, 112, 2015.

103. Laurencin, C., Khan, Y., and El-Amin, S.F. Bone graft substitutes. Expert Rev Med Devices 3, 49, 2006.

104. Shah, N.J., Macdonald, M.L., Beben, Y.M., Padera, R.F., Samuel, R.E., and Hammond, P.T. Tunable dual growth 
factor delivery from polyelectrolyte multilayer films. Biomaterials 32, 6183, 2011.

105. Sundelacruz, S., and Kaplan, D.L. Stem cell- and scaffoldbased tissue engineering approaches to osteochondral regenerative medicine. Semin Cell Dev Biol 20, 646, 2009.

106. Puppi, D., Chiellini, F., Piras, A.M., and Chiellini, E. Polymeric materials for bone and cartilage repair. Prog Polym Sci 35, 403, 2010.

107. Lee, C.H., Cook, J.L., Mendelson, A., Moioli, E.K., Yao, H., and Mao, J.J. Regeneration of the articular surface of the rabbit synovial joint by cell homing: a proof of concept study. Lancet 376, 440, 2010.

108. Karp, J.M., and Leng Teo, G.S.L. Mesenchymal stem cell homing: the devil is in the details. Cell Stem Cell 4, 206, 2009.

109. Discher, D.E., Mooney, D.J., and Zandstra, P.W. Growth factors, matrices, and forces combine and control stem cells. Science 324, 1673, 2009.

110. Dunehoo, A.L., Anderson, M., Majumdar, S., Kobayashi, N., Berkland, C., and Siahaan, T.J. Cell adhesion molecules for targeted drug delivery. J Pharm Sci 95, 1856, 2006.

111. Pierschbacher, M.D., and Ruoslahti, E. Variants of the cell recognition site of fibronectin that retain attachmentpromoting activity. Proc Natl Acad Sci U S A 81, 5985, 1984.

112. Ruoslahti, E., and Pierschbacher, M.D. Arg-Gly-Asp: a versatile cell recognition signal. Cell 44, 517, 1986.

113. Hersel, U., Dahmen, C., and Kessler, H. RGD modified polymers: biomaterials for stimulated cell adhesion and beyond. Biomaterials 24, 4385, 2003.

114. Kim, J.Y., Xin, X., Moioli, E.K., et al. Regeneration of dental-pulp-like tissue by chemotaxis-induced cell homing. Tissue Eng A 16, 3023, 2010.

115. Si, Y., Tsou, C.L., Croft, K., and Charo, I.F. CCR2 mediates hematopoietic stem and progenitor cell trafficking to sites of inflammation in mice. J Clin Invest 120, 1192, 2010.

116. Sarkar, D., Spencer, J.A., Phillips, J.A., et al. Engineered cell homing. Blood 118, e184, 2011.

117. Man, Z., Yin, L., Shao, Z., et al. The effects of co-delivery of BMSC-affinity peptide and rhTGF-betal from coaxial electrospun scaffolds on chondrogenic differentiation. Biomaterials 35, 5250, 2014.

118. Zhu, H., Yu, D., Zhou, Y., et al. Biological activity of a nanofibrous barrier membrane containing bone morphogenetic protein formed by core-shell electrospinning as a sustained delivery vehicle. J Biomed Mater Res B Appl Biomater 101, 541, 2013.

119. Huang, H., Zhang, X., Hu, X., et al. A functional biphasic biomaterial homing mesenchymal stem cells for in vivo cartilage regeneration. Biomaterials 35, 9608, 2014.

120. Dinopoulos, H., and Giannoudis, P.V. The use of bone morphogenetic proteins (BMPs) in long-bone non-unions. Curr Orthop 21, 268, 2007.

121. McKay, W.F., Peckham, S.M., and Badura, J.M. A comprehensive clinical review of recombinant human bone morphogenetic protein-2 (INFUSE $\left({ }^{\circledR}\right)$ Bone Graft). Int Orthop 31, 729, 2007.

122. Nune, K.C., Kumar, A., Murr, L.E., and Misra, R.D.K. Interplay between self-assembled structure of bone morphogenetic protein-2 (BMP-2) and osteoblast functions in three-dimensional titanium alloy scaffolds: stimulation of osteogenic activity. J Biomed Mater Res A 104, 517, 2016.
123. Karageorgiou, V., Meinel, L., Hofmann, S., Malhotra, A., Volloch, V., and Kaplan, D. Bone morphogenetic protein2 decorated silk fibroin films induce osteogenic differentiation of human bone marrow stromal cells. J Biomed Mater Res A 71, 528, 2004.

124. Reichert, J.C., Cipitria, A., Epari, D.R., et al. A tissue engineering solution for segmental defect regeneration in load-bearing long bones. Sci Transl Med 4, 141ra93, 2012.

125. Ong, K.L., Villarraga, M.L., Lau, E., Carreon, L.Y., Kurtz, S.M., and Glassman, S.D. Off-label use of bone morphogenetic proteins in the United States using administrative data. Spine (Phila Pa 1976) 35, 1794, 2010.

126. Epstein, N.E. Complications due to the use of BMP/INFUSE in spine surgery: the evidence continues to mount. Surg Neurol Int 4(Suppl. 5), S343, 2013.

127. Hyzy, S.L., Olivares-Navarrete, R., Schwartz, Z., and Boyan, B.D. BMP2 induces osteoblast apoptosis in a maturation state and noggin-dependent manner. J Cell Biochem 113, 3236, 2012.

128. Santo, V.E., Gomes, M.E., Mano, J.F., and Reis, R.L. Controlled release strategies for bone, cartilage, and osteochondral engineering-Part II: challenges on the evolution from single to multiple bioactive factor delivery, Tissue Eng Part B Rev 19, 327, 2013.

129. Gothard, D., Smith, E.L., Kanczler, J.M., et al. Tissue engineered bone using select growth factors: a comprehensive review of animal studies and clinical translation studies in man. Eur Cells Mater 28, 2014, 166. discussion, 207-8.

130. Salgado, A.J., Coutinho, O.P., and Reis, R.L. Bone tissue engineering: state of the art and future trends. Macromol Biosci 4, 743, 2004.

131. Falah, M., Nierenberg, G., Soudry, M., Hayden, M., and Volpin, G. Treatment of articular cartilage lesions of the knee. Int Orthop 34, 621, 2010.

132. Sridhar, B.V., Brock, J.L., Silver, J.S., Leight, J.L., Randolph, M.A., and Anseth, K.S. Development of a cellularly degradable PEG hydrogel to promote articular cartilage extracellular matrix deposition. Adv Healthc Mater 4, 702, 2015.

133. Jayaraman, P., Gandhimathi, C., Venugopal, J.R., Becker, D.L., Ramakrishna, S., and Srinivasan, D.K. Controlled release of drugs in electrosprayed nanoparticles for bone tissue engineering. Adv Drug Deliv Rev 94, 77, 2015.

134. Gupta, D., Venugopal, J., Mitra, S., Giri Dev, V.R.G., and Ramakrishna, S. Nanostructured biocomposite substrates by electrospinning and electrospraying for the mineralization of osteoblasts. Biomaterials 30, 2085, 2009.

135. Li, X., and Chen, H. Yb3+/Ho3+ co-doped apatite upconversion nanoparticles to distinguish implanted material from bone tissue. Appl Mater Interfaces 8, 27458, 2016.

136. Schnabel, M., Marlovits, S., Eckhoff, G., et al. Dedifferentiation-associated changes in morphology and gene expression in primary human articular chondrocytes in cell culture. Osteoarthritis Cartilage 10, 62, 2002.

137. Leslie, S.K., Cohen, D.J., Sedlaczek, J., Pinsker, E.J., Boyan, B.D., and Schwartz, Z. Controlled release of rat adipose-derived stem cells from alginate microbeads. Biomaterials 34, 8172, 2013.

138. Fedorovich, N.E., De Wijn, J.R., Verbout, A.J., Alblas, J., and Dhert, W.J. Three-dimensional fiber deposition of cell-laden, viable, patterned constructs for bone tissue printing. Tissue Eng A 14, 127, 2008. 
139. Fedorovich, N.E., Schuurman, W., Wijnberg, H.M., et al. Biofabrication of osteochondral tissue equivalents by printing topologically defined, cell-laden hydrogel scaffolds. Tissue Eng C Methods 18, 33, 2012.

140. Rezwan, K., Chen, Q.Z., Blaker, J.J., and Boccaccini, A.R. Biodegradable and bioactive porous polymer/inorganic composite scaffolds for bone tissue engineering. Biomaterials 27, 3413, 2006.

141. Logeart-Avramoglou, D., Anagnostou, F., Bizios, R., and Petite, H. Engineering bone: challenges and obstacles. J Cell Mol Med 9, 72, 2005.

142. Ferraris, S., and Spriano, S. Antibacterial titanium surfaces for medical implants. Mater Sci Eng C Mater Biol Appl 61, 965, 2016.

143. Kumar, S., Raj, S., Kolanthai, E., Sood, A.K., Sampath, S., and Chatterjee, K. Chemical functionalization of graphene to augment stem cell osteogenesis and inhibit biofilm formation on polymer composites for orthopedic applications. Appl Mater Interfaces 7, 3237, 2015.

144. Chavassieux, P.M., Chenu, C., Valentin-Opran, A., et al. Influence of experimental conditions on osteoblast activity in human primary bone cell cultures. J Bone Miner Res 5, 337, 1990.

145. Olivares-Navarrete, R., Raines, A.L., Hyzy, S.L., et al. Osteoblast maturation and new bone formation in response to titanium implant surface features are reduced with age. J Bone Miner Res 27, 1773, 2012.

146. Kohli, N., Wright, K.T., Sammons, R.L., Jeys, L., Snow, M., and Johnson, W.E.B. An in vitro comparison of the incorporation, growth, and chondrogenic potential of human bone marrow versus adipose tissue mesenchymal stem cells in clinically relevant cell scaffolds used for cartilage repair. Cartilage 6, 252, 2015.

147. Banfi, A., Muraglia, A., Dozin, B., Mastrogiacomo, M., Cancedda, R., and Quarto, R. Proliferation kinetics and differentiation potential of ex vivo expanded human bone marrow stromal cells: implications for their use in cell therapy. Exp Hematol 28, 707, 2000.

148. Nunamaker, D.M. Experimental models of fracture repair. Clin Orthop Relat Res 1998, S56, 1998.

149. Lang, T.F. The bone-muscle relationship in men and women. J Osteoporos 2011, 702735, 2011.

150. Lorenz, J., and Grässel, S. Experimental osteoarthritis models in mice. Methods Mol Biol 1194, 401, 2014.

151. Little, C.B., and Smith, M.M. Animal models of osteoarthritis. Curr Rheumat 4, 175, 2008.

152. McIlwraith, C.W., Frisbie, D.D., and Kawcak, C.E. The horse as a model of naturally occurring osteoarthritis. Bone Joint Res 1, 297, 2012.
153. Beutel, B.G., Danna, N.R., Granato, R., et al. Implant design and its effects on osseointegration over time within cortical and trabecular bone. J Biomed Mater Res A 104, 1091, 2016.

154. Hutmacher, D.W., Schantz, J.T., Lam, C.X.F., Tan, K.C., and Lim, T.C. State of the art and future directions of scaffold-based bone engineering from a biomaterials perspective. J Tissue Eng Regen Med 1, 245, 2007.

155. Einhorn, T.A. Clinically applied models of bone regeneration in tissue engineering research. Clin Orthop Relat Res 1999, S59, 1999.

156. Guillotin, B., and Guillemot, F. Cell patterning technologies for organotypic tissue fabrication. Trends Biotechnol 29, 183, 2011.

157. Barron, J.A., Krizman, D.B., and Ringeisen, B.R. Laser printing of single cells: statistical analysis, cell viability, and stress. Ann Biomed Eng 33, 121, 2005.

158. Simon, C.G., Jr., Yaszemski, M.J., Ratcliffe, A., Tomlins, P., Luginbuehl, R., and Tesk, J.A. ASTM international workshop on standards and measurements for tissue engineering scaffolds. J Biomed Mater Res B Appl Biomater 103, 949, 2015.

159. Ikada, Y. Challenges in tissue engineering. J R Soc Interface 3, 589, 2006.

160. Motamedian, S.R., Hosseinpour, S., Ahsaie, M.G., and Khojasteh, A. Smart scaffolds in bone tissue engineering: a systematic review of literature. World J Stem Cells 7, 657, 2015.

161. Crowley, C., Wong, J.M., Fisher, D.M., and Khan, W.S. A systematic review on preclinical and clinical studies on the use of scaffolds for bone repair in skeletal defects. Curr Stem Cell Res Ther 8, 243, 2013.

Address correspondence to: Haifeng Chen, PhD Department of Biomedical Engineering Peking University No. 5 Yiheyuan Road Beijing 100871

China

E-mail: haifeng.chen@pku.edu.cn

Received: May 3, 2018

Accepted: August 1, 2018

Online Publication Date: September 20, 2018 